\title{
Overview of the European "Particulates" Project on the Characterization of Exhaust Particulate Emissions from Road Vehicles: Results for Light-Duty Vehicles
}

\author{
Leonidas Ntziachristos, Athanasios Mamakos and Zissis Samaras \\ Laboratory of Applied Thermodynamics / Aristotle University Thessaloniki
}

Urs Mathis and Martin Mohr

Swiss Federal Laboratories for Materials Testing and Research (EMPA)

Neville Thompson

CONCAWE

Richard Stradling

Shell Global Solutions

Laurent Forti

IFP

Claes de Serves

AVL MTC

\begin{abstract}
This paper presents an overview of the results on light duty vehicles collected in the "PARTICULATES" project which aimed at the characterization of exhaust particle emissions from road vehicles. A novel measurement protocol, developed to promote the production of nucleation mode particles over transient cycles, has been successfully employed in several labs to evaluate a wide range of particulate properties with a range of light duty vehicles and fuels. The measured properties included particle number, with focus separately on nucleation mode and solid particles, particle active surface and total mass. The vehicle sample consisted of 22 cars, including conventional diesels, particle filter equipped diesels, port fuel injected and direct injection spark ignition cars. Four diesel and three gasoline fuels were used, mainly differentiated with respect to their sulfur content which was ranging from 300 to below $10 \mathrm{mg} / \mathrm{kg}$. All data (both real time and integrated) were collected in a common data base and centrally analyzed using common formats and methodologies, in order to eliminate inconsistencies and optimize comparability. Results show that particulate emissions are dramatically reduced by the combination of particulate traps and low sulfur fuels. However, particulate emissions patterns are also shown to differ between type approval and motorway driving conditions; this applying to both vehicle
\end{abstract}

technology and fuel sulfur effects; the latter becoming more obvious under high temperature conditions. The relevance of the current emissions certification cycle should be considered with regard to next steps in vehicle emissions legislation and the various vehicle technologies that are expected to be introduced. The study provides evidence that both particle number and active surface measurements offer the potential for greater sensitivity in evaluating particulate emissions, without any significant increase in the variability of results. More importantly, the study revealed that the usage of a dedicated sampling procedure is in the position to yield sufficiently repeatable results of solid and total particle populations, especially over transient tests.

\section{INTRODUCTION}

For several years, particulate matter (PM) emission levels from diesel light duty and heavy duty vehicles have been decreasing as an outcome of the implementation of continuously more stringent emission standards worldwide. To put it into perspective, while a diesel car corresponded to almost 50-100 gasoline vehicles when PM levels were concerned in the early 90s [1], the equivalency will become one to ten or less for European 2005 emission standards. For diesel particle filter (DPF) equipped diesel vehicles, PM emissions can be even 
lower than gasoline vehicles, especially when direct injection gasoline vehicles are considered. This situation has promoted two major research directions to support relevant policy development: (a) the detailed study of diesel PM emissions to understand their formation, impact and control and, (b) the study of PM from all vehicle types, including gasoline vehicles.

In this direction, the European Commission launched a three year research program ("PARTICULATES") on the characterization of exhaust aerosol from light and heavy duty vehicles. The project initially assessed the existing evidence and methodologies on particulate emissions [2] and concluded that, for this research program, both solid "accumulation mode" and volatile "nucleation mode" particles should be assessed. The nucleation mode presented a particular challenge which extended the methodology development phase. Nevertheless, the project completed in September 2003 and delivered a methodology for detailed sampling and analysis of collected aerosol from all vehicle types, capable of measuring both modes of particles from a minimum size range of ca $7 \mathrm{~nm}$ [3]. Based on this methodology and the associated measurement protocol, a significant number of light and heavy duty diesel vehicles and gasoline cars were measured. This paper presents an overview of the information collected from tests on light duty vehicles. The results on heavy duty vehicles will be reported elsewhere.

It is expected that findings from this project will contribute to efforts at an international level on the sampling and understanding of exhaust particle emissions. The methodologies and results supplement other work in the field, such as the UK DETR/SMMT/CONCAWE program $[4,5,6]$, relevant projects sponsored by CRC in US [7], ACEA particulates projects $[8,9]$ and the UN-ECE Particle Measurement Program [10].

This paper tries to assist in considerations of next steps in particulate emissions policy development, by providing new experimental data and a broad comparison with the earlier work in the field.

\section{EXPERIMENTAL}

VEHICLE MATRIX - Light duty vehicle testing has been performed in 6 individual laboratories:

- AVL MTC, Sweden

- Institut Français du Pétrole (IFP), France

- Swiss Federal Laboratories for Materials Testing and Research (EMPA), Switzerland

- Ford Forschungszentrum Aachen (FFA), Germany

- Laboratory of Applied Thermodynamics (LAT), Greece

- Shell Global Solutions (Shell), UK

The test sample consists of 22 individual vehicles, including conventional diesel vehicles, diesel vehicles fitted with particle filters (DPFs), conventional port injection spark ignition (PISI) and direct injection spark ignition (DISI). Table 1 presents these vehicles in some detail.

The diesel vehicle matrix includes 5 Euro 3 (Year 2000) vehicles, with the same VW Golf TDI measured by both Shell and Ford. There are also two Euro 2 vehicles. The Euro 2 vehicle measured at LAT was also measured with its catalyst removed in an attempt to simulate Euro 1 emission levels.

Table 1: Vehicle sample characteristics

\begin{tabular}{|c|c|c|c|c|c|}
\hline Concept & Lab & $\begin{array}{c}\text { Vehicle } \\
\text { Type }\end{array}$ & $\begin{array}{l}\text { Engine } \\
\text { Size [l] }\end{array}$ & $\begin{array}{l}\text { Emission } \\
\text { Standard }\end{array}$ & $\begin{array}{c}\text { After- } \\
\text { Treatment }\end{array}$ \\
\hline \multirow{9}{*}{ Diesel } & LAT & VW Golf TDI & 1.9 & $\begin{array}{l}\text { Euro } 1 \\
\text { (simul.) }\end{array}$ & None \\
\hline & LAT & VW Golf TDI & 1.9 & Euro 2 & OxiCat \\
\hline & AVL MTC & $\begin{array}{c}\text { Peugeot } 406 \\
\text { HDI }\end{array}$ & 2.0 & Euro 2 & OxiCat \\
\hline & LAT & $\begin{array}{c}\text { Renault } \\
\text { Laguna dCi }\end{array}$ & 1.9 & Euro 3 & OxiCat \\
\hline & IFP & VW Golf TDI & 1.9 & Euro 3 & OxiCat \\
\hline & FFA & VW Golf TDI & 1.9 & Euro 3 & OxiCat \\
\hline & EMPA & $\begin{array}{c}\text { Ford Galaxy } \\
\text { TD }\end{array}$ & 1.9 & Euro 3 & OxiCat \\
\hline & AVL MTC & VW Golf TDI & 1.9 & Euro 3 & OxiCat \\
\hline & Shell & VW Golf TDI & 1.9 & Euro 3 & OxiCat \\
\hline \multirow{5}{*}{$\begin{array}{c}\text { Diesel + } \\
\text { DPF }\end{array}$} & EMPA & $\begin{array}{c}\text { Peugeot } 406 \\
\text { HDI/FAP }\end{array}$ & 2.0 & Euro 3+ & $\begin{array}{l}\text { OxiCat }+ \\
\text { DPF }\end{array}$ \\
\hline & IFP & $\begin{array}{c}\text { Peugeot } 307 \\
\text { SW }\end{array}$ & 2.0 & Euro 3+ & $\begin{array}{c}\text { OxiCat }+ \\
\text { DPF } \\
\end{array}$ \\
\hline & LAT & $\begin{array}{c}\text { Renault } \\
\text { Laguna dCi }\end{array}$ & 1.9 & Euro 3+ & $\begin{array}{l}\text { OxiCat }+ \\
2 x D P F\end{array}$ \\
\hline & AVL MTC & $\begin{array}{c}\text { Peugeot } 607 \\
\text { HDI }\end{array}$ & 2.2 & Euro 3+ & $\begin{array}{l}\text { OxiCat }+ \\
\text { DPF }\end{array}$ \\
\hline & Shell & $\begin{array}{c}\text { Peugeot } 607 \\
\text { HDI }\end{array}$ & 2.2 & Euro 3+ & $\begin{array}{l}\text { OxiCat }+ \\
\text { DPF }\end{array}$ \\
\hline \multirow{6}{*}{$\begin{array}{c}\text { Gasoline } \\
\text { Port } \\
\text { Fuel } \\
\text { Injection }\end{array}$} & LAT & BMW 318ti & 1.8 & Euro 1 & TWC \\
\hline & IFP & $\begin{array}{c}\text { Renault } \\
\text { Mégane II }\end{array}$ & 1.6 & Euro 3 & TWC \\
\hline & LAT & $\begin{array}{l}\text { Toyota } \\
\text { Corolla TS }\end{array}$ & 1.8 & Euro 3 & TWC \\
\hline & EMPA & $\begin{array}{c}\text { Alfa } 146 \mathrm{TS} \\
16 \mathrm{~V} \\
\end{array}$ & 2.0 & Euro 3 & TWC \\
\hline & EMPA & $\begin{array}{c}\text { Renault } \\
\text { Mégane } 16 \mathrm{~V}\end{array}$ & 1.6 & Euro 3 & TWC \\
\hline & AVL MTC & $\begin{array}{l}\text { Honda } \\
\text { Accord }\end{array}$ & 2.2 & ULEV & TWC \\
\hline \multirow{2}{*}{$\begin{array}{l}\text { Stoich. } \\
\text { DISI }\end{array}$} & EMPA & $\begin{array}{c}\text { Toyota } \\
\text { Avensis }\end{array}$ & 2.0 & Euro 3 & TWC \\
\hline & Shell & $\begin{array}{c}\text { Renault } \\
\text { Mégane IDE }\end{array}$ & 2.0 & Euro 3 & TWC \\
\hline \multirow{3}{*}{$\begin{array}{l}\text { Lean } \\
\text { DISI }\end{array}$} & AVL MTC & $\begin{array}{c}\text { Mitsubishi } \\
\text { Carisma GDI }\end{array}$ & 1.8 & Euro 3 & $\begin{array}{l}\text { TWC/NOx } \\
\text { Storage }\end{array}$ \\
\hline & IFP & $\begin{array}{c}\text { Peugeot } 406 \\
\text { HPI }\end{array}$ & 2.0 & Euro 3 & $\begin{array}{l}\text { TWC/NOx } \\
\text { storage }\end{array}$ \\
\hline & Shell & $\begin{array}{c}\text { Citroen C5 } \\
\text { HPI }\end{array}$ & 2.0 & Euro 3 & $\begin{array}{l}\text { TWC/NOx } \\
\text { Storage }\end{array}$ \\
\hline
\end{tabular}

The diesel vehicles equipped with OEM DPFs were also Euro 3 certified but their PM emission level already complied with Euro 4 emission standards (hence designated as Euro 3+). The Renault Laguna measured at LAT was retrofitted with two different DPF systems, one with fuel borne catalyst and one with a catalyzed filter. For the particular vehicle, the measurements reported here correspond to a freshly regenerated DPF. 
Six conventional (port fuel injection spark ignition) gasoline vehicles were tested, all equipped with three way catalytic converters. Of these, four were Euro 3, one was Euro 1 and one was certified to the Californian ULEV emission standards.

Finally, five direct injection spark ignition (DISI) passenger cars were included in the sample. Two operated in stoichiometric mode with conventional three way catalysts (TWCs) and three operated in lean mode where a NOx adsorber catalyst complemented the TWC. All vehicles were Euro 3 compliant.

With respect to the condition of vehicles, all were well maintained and of limited mileage $(<50000 \mathrm{~km})$. The only exceptions were the ULEV and Euro 1 gasoline cars which had been operated in excess of $100000 \mathrm{~km}$.

The coverage of technologies other than Euro 3 (conventional and with particle filters) is very limited. Hence, it is not expected that this sample is sufficient to demonstrate the impact of different emission standards on particle characteristics. However, information on non Euro 3 technologies is included to contrast to Euro 3 levels in specific cases and better clarify individual performance.

FUEL MATRICES - The core test fuels were selected based on the objectives to develop input on representative emission factors for current and future vehicle fleets as well as to enhance understanding of fuel effects. Existing knowledge indicated fuel sulfur as a key fuel effect on particle emissions, both in terms of enabling new exhaust after-treatment technology and as a direct effect on sulfate emissions. Consequently, the updated EU Fuels Directive requires the introduction of sulfur-free fuels $(10 \mathrm{mg} / \mathrm{kg}$ max sulfur) starting in 2005 [11].

In view of the above, the test fuels were mainly designed around the sulfur effect, using base fuels with other properties held as close as possible to average year $2000 / 05$ levels given the available blending components, but with sulfur content as low as possible. Sulfur levels of both diesel and gasoline fuels were adjusted to current, 2005 and 2009 levels by doping with sulfur compounds, thiophene and di-tertiarybutyl-disulphide. The main properties of the fuels developed are shown in Table 2. The conventions D2, D3 and D4 and G1, G2 and G3 are used for diesel fuels and gasoline fuels of decreasing sulfur content, respectively.

In addition to the fuel matrix specifically developed for this project, an additional sulfur-free fuel, Swedish Environmental Class 1 (D5), was also tested in order to assess any further potential benefits from extreme changes to other fuel properties.

LUBRICANT - It is also expected that lubricating oil may have an effect on the characteristics of particles emitted from each vehicle. In order to minimize any lubricant effects, a common batch of lubricant was used for the program. A typical high volume and conventional oil formulation was used for all vehicles examined, which met the following specifications:

- Viscosity type: $15 \mathrm{~W}-40$

- ACEA Class A3/B3

- Sulfur content: 6000 ppm w/w.

Table 2: Main diesel and gasoline fuel properties

\begin{tabular}{|c|c|c|c|c|c|}
\hline \multicolumn{3}{|c|}{ DIESEL FUELS } & \multicolumn{3}{|c|}{ GASOLINE FUELS } \\
\hline Property & $\begin{array}{c}\text { D2 to } \\
\text { D4 }\end{array}$ & D5 & Property & G1 & $\begin{array}{c}\text { G2 to } \\
\text { G3 }\end{array}$ \\
\hline $\begin{array}{l}\text { Cetane } \\
\text { Number }\end{array}$ & 54.0 & 55.1 & RON & 96.4 & 96.8 \\
\hline $\begin{array}{l}\text { Cetane } \\
\text { Index }\end{array}$ & 51.1 & 51.7 & MON & 85.3 & 86.0 \\
\hline $\begin{array}{l}\text { Density } \\
\left(\mathrm{kg} / \mathrm{m}^{3}\right)\end{array}$ & 845 & 810 & $\begin{array}{l}\text { Density } \\
\left(\mathrm{kg} / \mathrm{m}^{3}\right)\end{array}$ & 753 & 749 \\
\hline $\mathrm{T} 50\left({ }^{\circ} \mathrm{C}\right)$ & 282 & 226 & $\mathrm{RVP}(\mathrm{kPa})$ & 58.7 & 57.7 \\
\hline T95 $\left({ }^{\circ} \mathrm{C}\right)$ & 358 & 282 & $\begin{array}{l}\text { E70 } \\
(\% \mathrm{v} / \mathrm{v})\end{array}$ & 29.4 & 32.5 \\
\hline $\operatorname{FBP}\left({ }^{\circ} \mathrm{C}\right)$ & 368 & 294 & $\begin{array}{l}\text { E100 } \\
(\% \mathrm{v} / \mathrm{v})\end{array}$ & 50 & 51.2 \\
\hline $\begin{array}{l}\text { Flash } \\
\text { point }\left({ }^{\circ} \mathrm{C}\right)\end{array}$ & 68 & 66 & $\begin{array}{l}\text { E150 } \\
(\% \mathrm{v} / \mathrm{v})\end{array}$ & 85.5 & 86.1 \\
\hline $\begin{array}{l}\text { CFPP } \\
\left({ }^{\circ} \mathrm{C}\right)\end{array}$ & -33 & -39 & FBP $\left({ }^{\circ} \mathrm{C}\right)$ & 195 & 193 \\
\hline $\begin{array}{l}\mathrm{KV} @ 40 \\
\mathrm{C}\left(\mathrm{mm}^{2} / \mathrm{s}\right)\end{array}$ & 3.04 & 1.79 & $\begin{array}{l}\text { Residue } \\
(\% \mathrm{v} / \mathrm{v})\end{array}$ & 1.0 & 1.1 \\
\hline $\begin{array}{l}\text { PAH } \\
(\% \mathrm{~m} / \mathrm{m})\end{array}$ & 4.3 & $<0.1$ & $\begin{array}{l}\text { Olefins } \\
(\% \mathrm{v} / \mathrm{v})\end{array}$ & 8.8 & 9.9 \\
\hline $\begin{array}{l}\text { Mono- } \\
\text { aromatics } \\
(\% \mathrm{~m} / \mathrm{m})\end{array}$ & 14.1 & 1.7 & $\begin{array}{l}\text { Aromatics } \\
(\% \mathrm{v} / \mathrm{v})\end{array}$ & 35.4 & 33.4 \\
\hline $\begin{array}{l}\text { Carbon } \\
(\% \mathrm{~m} / \mathrm{m})\end{array}$ & 86.8 & 85.9 & $\begin{array}{l}\text { Benzene } \\
(\% \mathrm{v} / \mathrm{v})\end{array}$ & 0.8 & 0.6 \\
\hline $\begin{array}{l}\text { Hydrogen } \\
(\% \mathrm{~m} / \mathrm{m})\end{array}$ & 13.2 & 14.4 & Lead $(\mathrm{mg} / \mathrm{l})$ & $<1$ & $<1$ \\
\hline $\mathrm{H}: \mathrm{C}$ ratio & $1.82: 1$ & $2.01: 1$ & $\begin{array}{l}\text { Phosphorus } \\
(\mathrm{mg} / \mathrm{l})\end{array}$ & $<1$ & $<1$ \\
\hline $\begin{array}{l}\mathrm{LHV} \\
(\mathrm{MJ} / \mathrm{kg})\end{array}$ & 42.8 & 43.9 & $\begin{array}{l}\text { Carbon } \\
(\% \mathrm{~m} / \mathrm{m})\end{array}$ & 86.3 & 86.0 \\
\hline $\begin{array}{l}\text { Water } \\
(\mathrm{mg} / \mathrm{kg})\end{array}$ & 36 & 35 & $\begin{array}{l}\begin{array}{l}\text { Hydrogen } \\
(\% \mathrm{~m} / \mathrm{m})\end{array} \\
\end{array}$ & 13.0 & 13.2 \\
\hline $\begin{array}{l}\text { HFRR } \\
(\mu \mathrm{m})\end{array}$ & 375 & 386 & $\begin{array}{l}\text { Oxygen } \\
(\% \mathrm{~m} / \mathrm{m}) \\
\end{array}$ & 0.7 & 0.8 \\
\hline Sulfur & $\mathrm{mg} / \mathrm{kg}$ & $\mathrm{mg} / \mathrm{kg}$ & Sulfur & $\mathrm{mg} / \mathrm{kg}$ & $\mathrm{mg} / \mathrm{kg}$ \\
\hline $\mathrm{D}-2$ & 280 & & G-1 & 143 & \\
\hline $\mathrm{D}-3$ & 38 & & G-2 & & 45 \\
\hline D-4 & 8 & & G-3 & & 6 \\
\hline $\mathrm{D}-5$ & & 3 & & & \\
\hline
\end{tabular}

DAILY TEST PROCEDURE - The standard NEDC emissions certification test for light duty vehicles was used as the core transient test for both gasoline and diesel light duty vehicle tests. The NEDC cycle has been used in Europe for certification of light duty vehicles since 2000 [12] and originates from the former ECE15 + EUDC procedure by elimination of the initial $40 \mathrm{~s}$ of idling. In addition, three real-world driving cycles which were developed in the framework of the ARTEMIS project [13] were measured. These cycles (Figure 1) 
were developed by statistical analysis of speed profile databases consisting of $90000 \mathrm{~km}$ monitored on board 80 passenger cars in France, Germany, Great Britain and Greece, supplemented by another $10000 \mathrm{~km}$ obtained in Switzerland and Italy under controlled traffic conditions. These cycles, named Common Artemis Driving Cycles (CADC) by convention, correspond to total of 40 minutes of urban, rural and motorway driving which describe a range of representative driving conditions encountered in Europe.

Further to the transient tests, three steady state speeds - 50, 90 and $120 \mathrm{~km} / \mathrm{h}$ - road load, were tested. This also enabled measurement of particle number/size distribution with instrumentation which requires steadystate conditions.
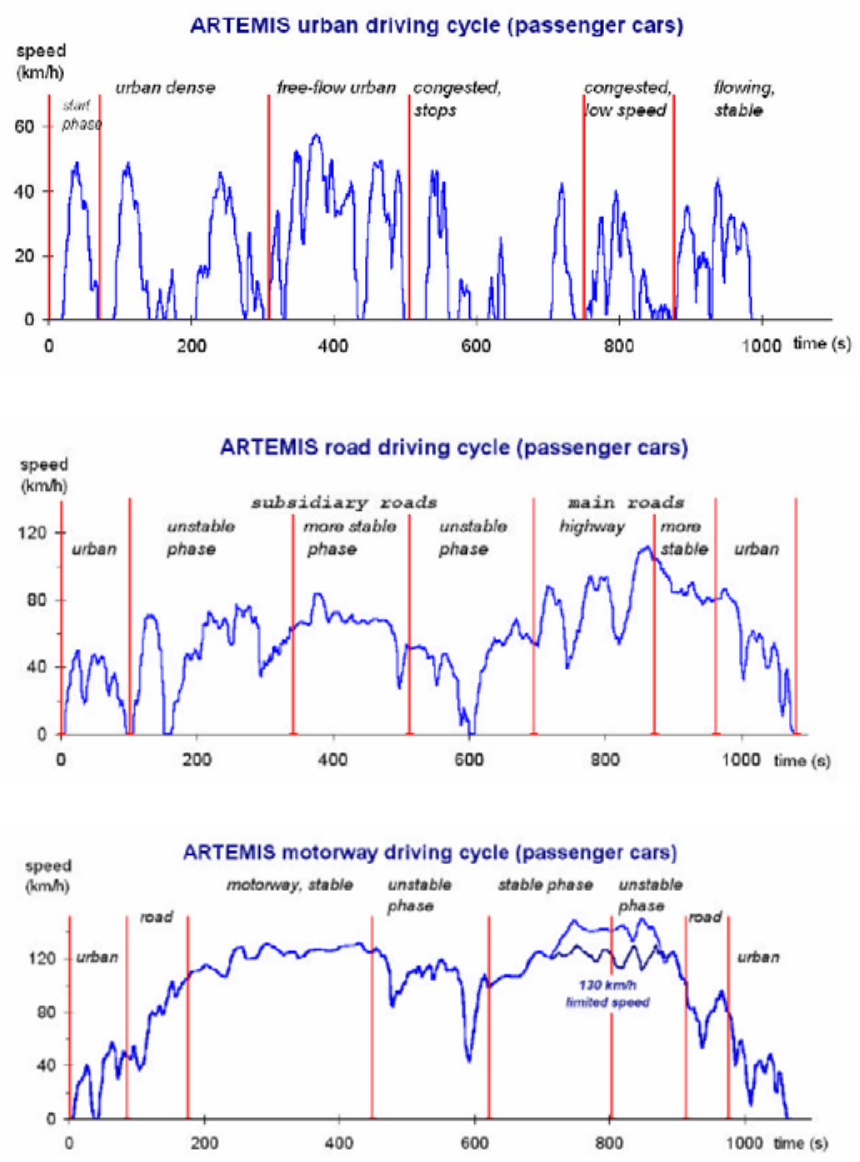

Figure 1: Speed profile of the three ARTEMIS cycles representing real world driving conditions and used for vehicle testing. Artemis Motorway has two options for high power and low power vehicles.

The different driving cycles and steady state modes were executed following the protocol shown in Figure 2. The protocol also prescribes the procedure following a fuel change and the vehicle conditioning before each measurement. After conditioning with each new fuel, the vehicle is driven over a series of a cold-start NEDC, a hot-start NEDC and the three CADC cycles. At the end, the three steady state tests were performed.
SAMPLING AND MEASUREMENT - The sampling system developed and applied for the characterization of exhaust aerosol has been presented in detail elsewhere [3] and its basic outline is shown in Figure 3. The main idea of the sampling system is to provide sampling conditions which favor nucleation mode formation and this is achieved by using a moderate primary dilution ratio (12.5:1) and cooling of the exhaust with conditioned air at $32^{\circ} \mathrm{C}$. Providing favorable sampling conditions, one reveals the potential for nucleation mode formation for a specific combination of vehicle, fuel and driving cycle. Subsequent secondary dilutors decrease the concentration to levels within the range of the different instruments, depending on the vehicle examined (conventional diesel, trap equipped diesel, gasoline, etc...). All instruments sample total particle populations, except of the ELPI which samples solid particles downstream of a thermodenuder.

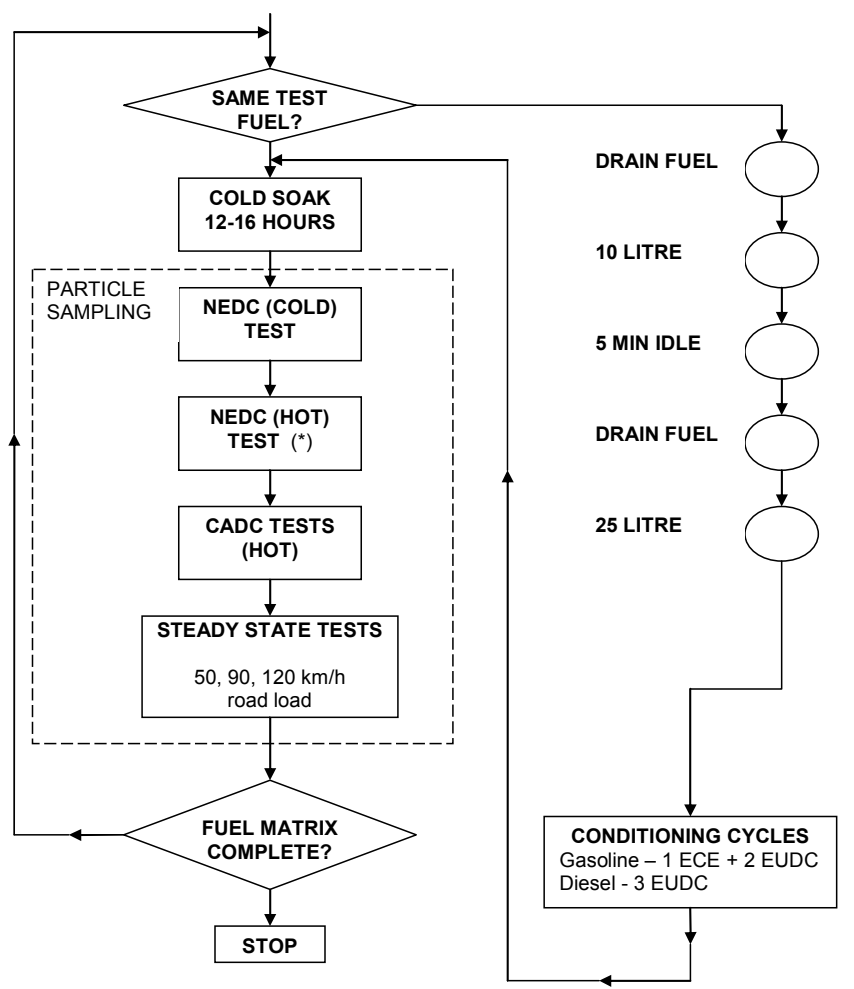

Figure 2: Daily test sequence with optional fuel change $\left({ }^{*}\right.$ this hotstart NEDC was replaced with its hot-start urban part only in some laboratories).

Based on the sampling system developed, Table 3 provides a summary of the aerosol information that is collected over a test. In addition to these, PM and regulated gaseous pollutants were measured during the tests, following the reference procedure based on the CVS.

DATA HANDLING AND QUALITY ASSURANCE - The large number of data collected over a single day of measurement together with the multiple physical environments where measurements were conducted, 
made the data handling and processing a demanding task. In order to eliminate inconsistencies that might arise from using different instrument software versions, calculation parameters and post processing, a central software application was developed which was used to store data and make all necessary calculations for all instruments involved in the different labs.

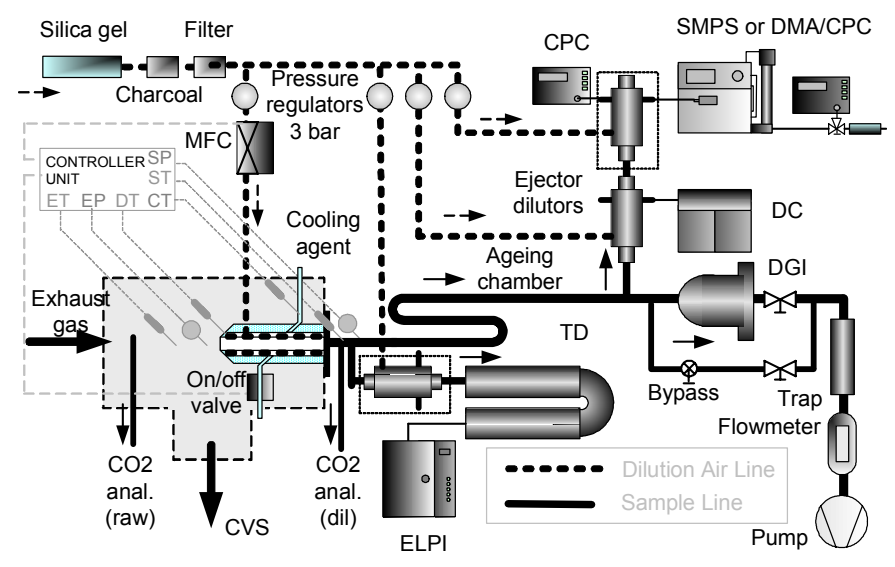

Figure 3: Sampling system used for characterization of exhaust aerosol.

Table 3: Aerosol information collected over a test

\begin{tabular}{|c|c|c|c|}
\hline Instrument & Property & $\begin{array}{c}\text { Size } \\
\text { resolution }\end{array}$ & $\begin{array}{c}\text { Temporal } \\
\text { resolution }\end{array}$ \\
\hline $\begin{array}{c}\text { Condensation } \\
\text { Particle Counter } \\
\text { (CPC) }\end{array}$ & $\begin{array}{c}\text { Particle } \\
\text { number } \\
\text { concentration }\end{array}$ & $\begin{array}{c}\text { One channel } \\
>7 \mathrm{~nm}\end{array}$ & $\begin{array}{c}1 \mathrm{~s} \\
\text { (transients) }\end{array}$ \\
\hline $\begin{array}{c}\text { Scanning } \\
\text { Mobility Particle } \\
\text { Sizer (SMPS) }\end{array}$ & $\begin{array}{c}\text { Particle } \\
\text { sizing and } \\
\text { concentration }\end{array}$ & $\begin{array}{c}64 \text { channels } \\
\text { per decade } \\
7-300 \mathrm{~nm} \text { or } \\
10-450 \mathrm{~nm}\end{array}$ & $\begin{array}{c}90 \mathrm{~s} \\
\text { (steady } \\
\text { states) }\end{array}$ \\
$\begin{array}{c}\text { Electrical Low } \\
\text { Pressure }\end{array}$ & $\begin{array}{c}\text { Solid particle } \\
\text { sizing and } \\
\text { Impactor (ELPI) } \\
+ \text { thermodenuder } \\
\text { (TD) }\end{array}$ & $\begin{array}{c}\text { Fonst } 8 \\
\text { considered } \\
\text { with filter } \\
\text { stage }\end{array}$ & $\begin{array}{c}1 \mathrm{~s} \\
\text { (transients) }\end{array}$ \\
\hline $\begin{array}{c}\text { Diffusion Charger } \\
\text { (DC) }\end{array}$ & Active surface & $\begin{array}{c}\text { One channel } \\
7 \mathrm{~nm}-1 \mu \mathrm{m}\end{array}$ & $\begin{array}{c}1 \mathrm{~s} \\
\text { (transients) }\end{array}$ \\
\hline $\begin{array}{c}\text { Gravimetric } \\
\text { Impactor (DGI) }\end{array}$ & $\begin{array}{c}\text { Mass-based } \\
\text { particle sizing }\end{array}$ & $\begin{array}{c}5 \mathrm{stages} \\
<10 \mu \mathrm{m}\end{array}$ & $\begin{array}{c}\text { Integral } \\
\text { over a test }\end{array}$ \\
\hline
\end{tabular}

A flowchart of the data handling process is presented in Figure 4. The individual files with data from each instrument, the lab instrumentation and the vehicle and fuel specifications are stored in a coded database format. A central application performs all calculations to produce integrated values over a cycle, starting with primary instrument signals and taking into account dilution ratios, flowrates, the necessary synchronization between the instruments and the driving conditions, and particle losses in the sampling system. The processed information is stored in an indexed database structure which allows easy extraction of any information necessary. Finally, a post-processing application enables the creation of charts for visualization of the data and statistical processing of the information.

Great care was taken to increase the comparability between the different laboratories involved by setting up similar sampling systems, utilizing an identical sampling protocol and developing a common application to process all data. Nevertheless, a certain degree of variability has to be expected in the data collected from different test laboratories. Ntziachristos et al. [3] demonstrated that the expected reproducibility between labs is in the range of $20-30 \%$. This should be considered as a reference baseline reproducibility. Obviously, there might be individual cases where larger differences between particular instruments and/or laboratories may exist. Such a range of variability should be taken into account when considering the significance of different effects.

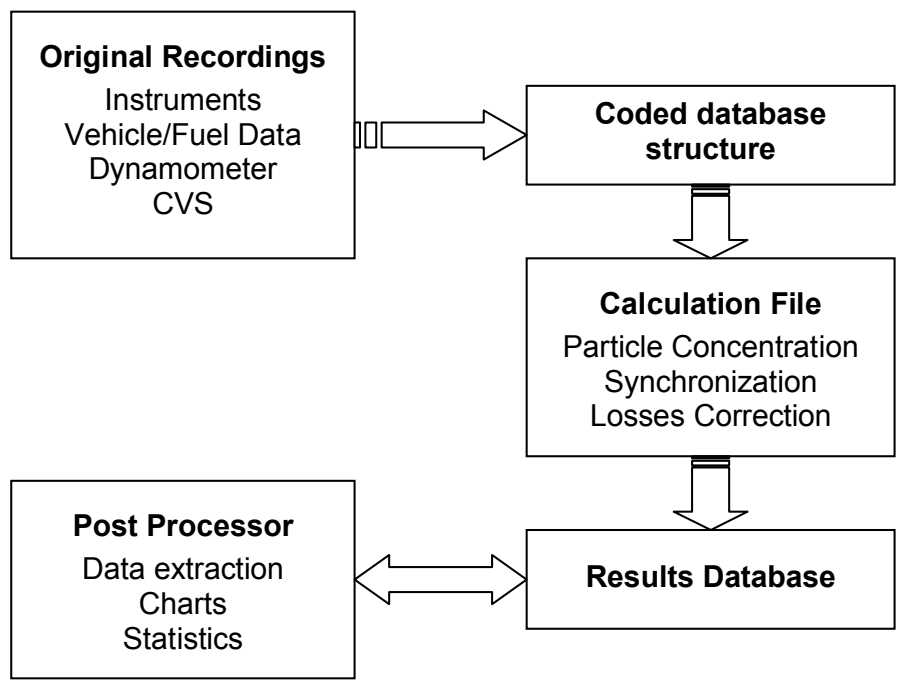

Figure 4: Data handling process flowchart.

\section{RESULTS}

In order to establish the absolute levels of different properties of particle emissions, Figure 5 a provides a plot of the regulated PM measurements of all vehicles, as listed in Table 2, tested over the standard NEDC procedure. Each point on the plot corresponds to the mean emission of a single vehicle over a single test on the particular cycle using the corresponding fuel in the abscissa. The NEDC is used at this stage to establish the emission level following the regulated procedure. This is a cycle mainly corresponding to urban and suburban driving, including a very short section of motorway driving. It also includes a cold start. The effect of the driving pattern on the emissions can be explored by choosing the Artemis Motorway (Figure $5 b$ ) to compare emissions against the regulated NEDC test. The Artemis Motorway cycle is a more severe motorway 
cycle as the name suggests which includes a hot start and a long high speed section. Therefore its overlap with the NEDC is limited and these two cycles can be used as a proxy for a wide range of driving conditions.
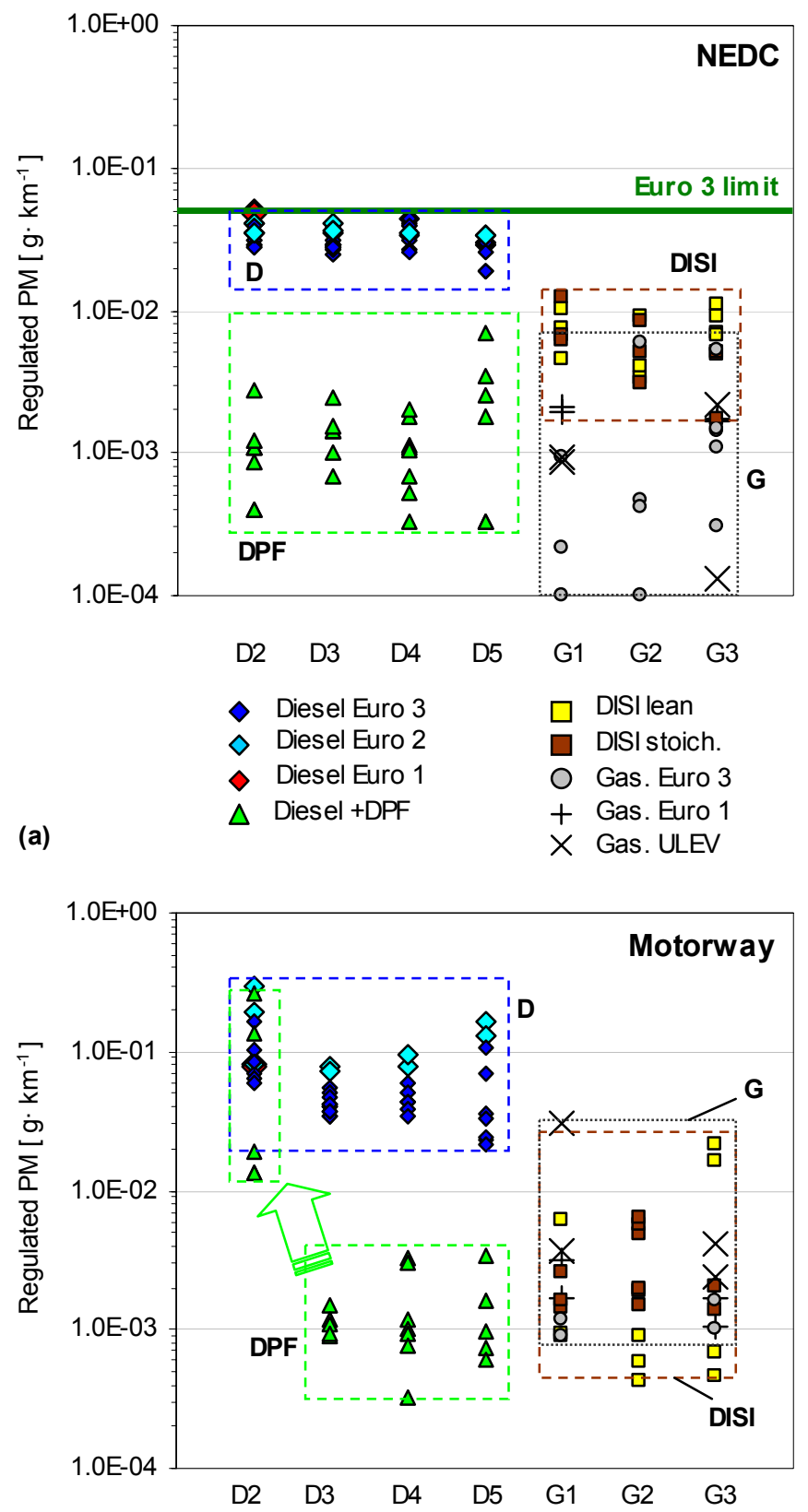

(b)

Figure 5: Regulated PM over (a) NEDC and (b) Artemis Motorway cycles.

In this paper we try to draw general conclusions concerning the effect of technology, fuel and driving cycle on the emissions, rather than focusing on the individual performance of each vehicle. In this respect we distinguish four different vehicle technologies, i.e. conventional diesel (D), diesel with particle filters (DPF), conventional gasoline $(G)$ and direct injection gasoline
(DISI). When necessary, a more detailed distinction according to the emission standards is done. The following sections provide the results per particle property, distinguishing between:

- The effect of vehicle technology over the regulated cycle in order to compare particle emissions of the different vehicles following the type-approval procedure.

- The effect of fuel, over the regulated cycle, to demonstrate the potential of different fuels in reducing emissions on the type-approval test.

- The effect of driving cycle on emissions in order to explore whether vehicle emission levels and fuel impacts are consistent for different driving conditions.

\section{REGULATED PM EMISSIONS}

Effect of vehicle technology - Figure 5a shows that there is a distinction between the regulated PM levels of the four groups of vehicle technologies. All $D$ vehicles complied with a margin with the Euro 3 emission standard $(50 \mathrm{mg} / \mathrm{km})$, including the two Euro 2 vehicles and the simulated Euro 1. This shows that the emission standards have been effective in regulating PM emissions from conventional diesel vehicles. It also shows however, that the Euro 2 vehicles and the simulated Euro 1 vehicle concerned may not be representative of their corresponding emission classes, because of their low emissions. This should be taken into account when considering emissions of other particle properties for these particular vehicles.

DPF emission levels are generally found below $3 \mathrm{mg} / \mathrm{km}$, consistent with emission levels reported for such vehicle technologies in all relevant studies. There is one measurement of a DPF vehicle reaching $7 \mathrm{mg} / \mathrm{km}$. Except of this case, DPFs seem at least $90 \%$ effective in reducing the mass of diesel passenger cars over the regulated cycle. This brings the emission levels at or below the detection limit of the current gravimetric procedure. This seems also responsible for the relatively large scatter of the DPF emission values.

DISI vehicles gave measurable PM emissions over the NEDC. Their emissions ranged from $4-11 \mathrm{mg} / \mathrm{km}$ and with the majority of measurements found below $10 \mathrm{mg} / \mathrm{km}$. These values are slightly higher than the emission levels reported in the work of ACEA [9] but they are within the range usually expected for DISI vehicles $[6,14]$.

G-vehicles are at the same level with DPF vehicles and reach the sensitivity limit of the method. The two older gasoline cars (ULEV and Euro 1) seem to emit more than the newer vehicles but still below $2.5 \mathrm{mg} / \mathrm{km}$. Such low levels raise questions whether the diesel-like regulated procedure is appropriate and sensitive enough to demonstrate the true PM emission level for such ultra 
low emitting vehicles [15]. This will be further discussed when different instruments are cross-compared.

Effect of fuel - Significant effect of fuels on PM emissions over the NEDC could only be measured for Dvehicles, due to the low emission level of all other vehicle technologies. In general, there was a strong overlap between D2, D3 and D4 fuels and there are no clear trends on fuel sulfur content over the NEDC. There was however an effect of the bulk fuel properties on PM emissions. Use of the D5 fuel reduced the average emission level of each vehicle by about $10-25 \%$. This is not particularly clear in Figure $5 a$ due to the difference in the emission levels of each vehicle which lead to an overlap between D5 and the other fuels. The reduction in PM with use of D5 cannot be directly related to any single fuel property; it may originate from its lower density compared to D2-D4, its very low aromatics level and negligible poly-aromatics content but is generally consistent with the findings of EPEFE [16].

Effect of driving cycle - There is a strong effect of the driving condition, in conjunction with the fuel used, on the PM emission level of the vehicles tested. Using D2 fuel, the Artemis Motorway results in very high emissions from all diesel vehicles; as high as $300 \mathrm{mg} / \mathrm{km}$ for one Euro 2 vehicle. In the same manner, all Euro 3 vehicles exceed the nominal emission standard $(50 \mathrm{mg} / \mathrm{km})$ by $20-250 \%$. Furthermore, the emission level of all DPF vehicles increases significantly and in one particular case it reaches $260 \mathrm{mg} / \mathrm{km}$ (Peugeot 607 measured at AVL MTC). On the other hand, the simulated Euro 1 vehicle, where the oxidation catalyst is removed, remains at a moderate level $(80 \mathrm{mg} / \mathrm{km})$.

These observations are consistent with sulfate storagerelease in the exhaust catalyst/line of the diesel vehicles and will be better demonstrated when looking different particle properties.

The effect of cycle is not evident with fuels D3 and D4, indicating that $50 \mathrm{ppm} S$ is about the level above which significant sulfate release becomes an issue. DPF equipped vehicles remain below $3-4 \mathrm{mg} / \mathrm{km}$, in consistency with their performance over the NEDC. In the same manner, Euro 3 D-vehicles over Artemis Motorway show only a slight but consistent increase of their emission level of $20-30 \%$ over the equivalent NEDC levels. This shows that there is a combined benefit of using lower sulfur fuels and advanced technology vehicles. On the other hand, the two Euro 2 vehicles show a higher increase in their emissions, which exceeds $100 \%$ when the D5 has been used, but this may also be a vehicle specific behavior.

Most of the DISI and G-vehicles remain at low emission levels (i.e. up to $7 \mathrm{mg} / \mathrm{km}$ ) for this demanding motorway cycle. One may observe both reductions and increases over the regulated NEDC, depending on the vehicle characteristics. Probably, this is the outcome of two competing effects: increase in emission levels during cold start (NEDC) versus increase during high power conditions (Artemis Motorway). In any case, PM emissions from both $G$ and DISI vehicles are found at similar levels for this high-power cycle, because all DISI vehicles then operate in stoichiometric mode. There are some isolated cases where emissions can reach up to $30 \mathrm{mg} / \mathrm{km}$ for both vehicle technologies. This may be due to enrichment of the fuel/air mixture or sulfate formation (when using G1).

Regulated PM Summary - Based on the observations in the previous sections, the following conclusions may be drawn for regulated PM emissions:

- Conventional diesel vehicles give relatively high PM emissions, which are however within the emission limit, at least for the regulated cycle.

- Trap equipped diesels operating on low sulfur (below $40 \mathrm{mg} / \mathrm{kg}$ ) fuels give near zero PM (at the limit of measurement) under all operating conditions.

- Exception to the above is the higher temperature conditions of the Artemis motorway and current diesel fuel sulfur content $(280 \mathrm{mg} / \mathrm{kg})$. Under these conditions trap equipped diesels were found to emit similar PM quantities to conventional diesels.

- Other fuel properties, e.g. density, impact PM emissions in conventional vehicles, but in DPF vehicles the impact on PM mass emissions is negligible.

- Conventional gasoline vehicles give very low PM emissions.

- DISl's give measurable PM (though well below diesel Euro-4 limit, an issue to be considered with respect to Euro-5).

It should also be remembered that additional benefits of fuel sulfur reduction are to enable a range of advanced after-treatment technologies, including various PM traps and to reduce sulfate impact on nano-particles. The latter will be considered further in the following sections.

\section{ACTIVE SURFACE}

In engineering terms, active surface is a surrogate for the specific particle surface area which is available for interaction with the environment, i.e. for gas-to-particle and particle-to-particle interactions. Active surface is recorded with diffusion chargers (DCs) and in this case it corresponds to particles in the range $7 \mathrm{~nm}-1 \mu \mathrm{m}$.

Effect of vehicle technology - Similar conclusions to PM are obtained when examining the effect of vehicle technology on active surface emissions (Figure 6a). However, there is a higher sensitivity of the DC technique which is demonstrated by the emissions of the sample vehicles spreading over a range of 5 orders of magnitude. Furthermore, DC emissions appear both reproducible and robust with coefficients of variance (COV) ranging between $19-28 \%$ for D-vehicles, depending on the fuel and vehicle (corresponding PM COV levels: $14-22 \%$ ). 
Active surface area for the D-vehicles is found at $10^{5} \mathrm{~cm}^{2} / \mathrm{km}$ with the Euro 1 vehicle operating on D2 found at the highest level. As in the case of PM, no large difference between the levels of Euro 2 and Euro 3 vehicles can be established. DISI vehicles are found one order of magnitude lower than D-vehicles, at $10^{4} \mathrm{~cm}^{2} / \mathrm{km}$ with a scatter of values between $1 \times 10^{3}$ and $6 \times 10^{4} \mathrm{~cm}^{2} / \mathrm{km}$. There are no consistent differences between stoichiometric and lean burn vehicles.

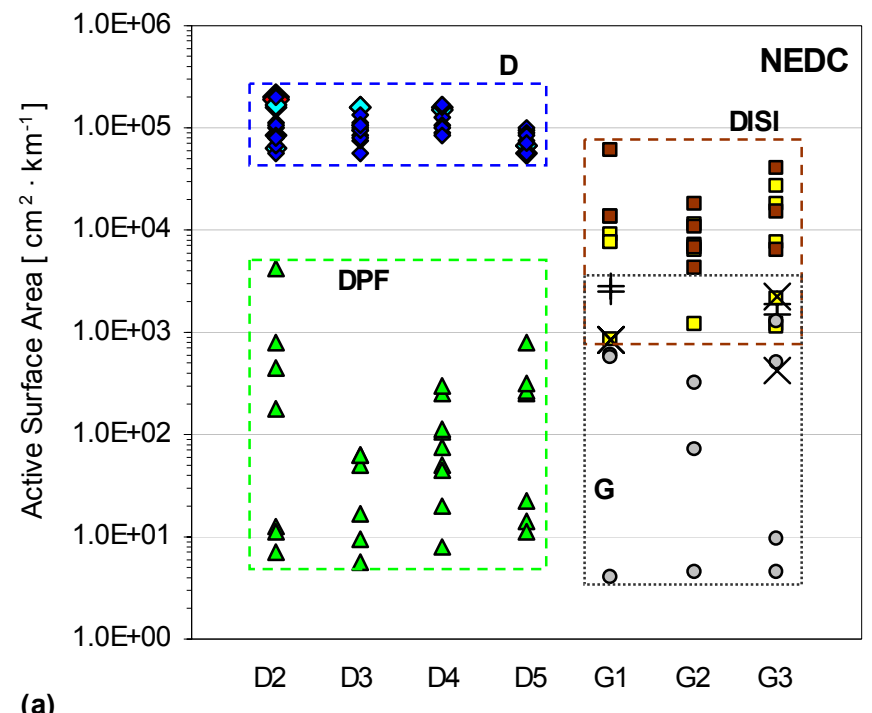

(a)

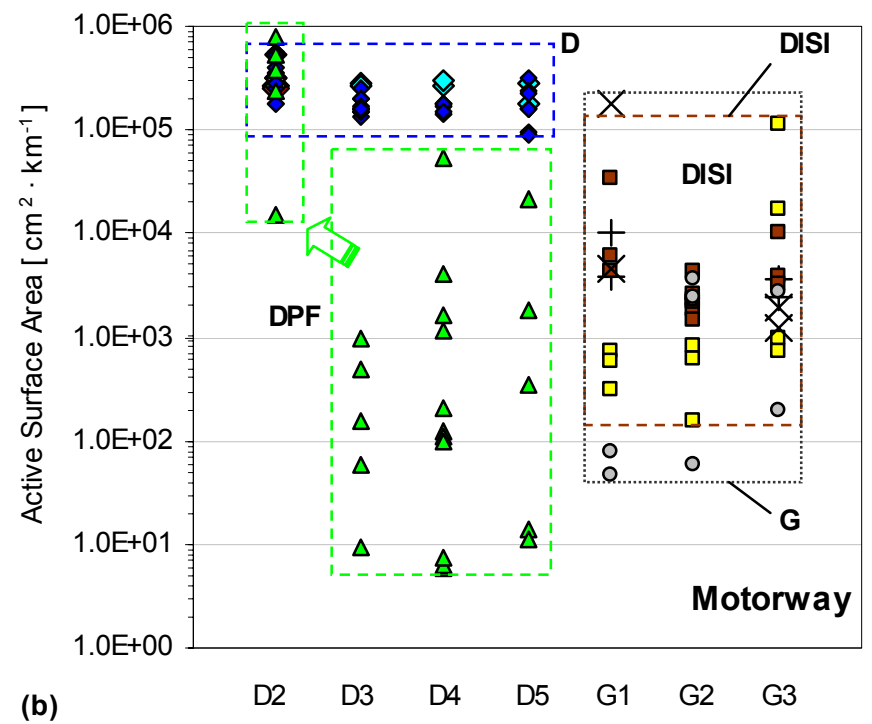

Figure 6: Integrated active surface area over (a) NEDC and (b) Artemis Motorway cycles. Symbols as in legend of Figure 5.

Emission levels of $G$ and DPF vehicles overlap and spread over three orders of magnitude $\left(5 \times 10^{0}\right.$ $5 \times 10^{3} \mathrm{~cm}^{2} / \mathrm{km}$ ), with a clear distinction from both $\mathrm{D}$ and DISI vehicles. For $G$ vehicles, older and much used vehicles (Euro 1 and ULEV) are found at the higher end of the range.
Effect of fuel - In direct analogy to the fuel effect on PM emissions, only D-vehicles with use of D5 show a consistent reduction of active surface which, on a vehicle basis, reaches $15-20 \%$.

For all other fuels and vehicle technologies, no consistent effect of fuel can be derived in the NEDC cycle.

Effect of driving cycle - The higher sensitivity of the DC measurement, compared to the gravimetric PM procedure is also demonstrated when the effect of driving cycle is concerned. Compared to the regulated NEDC, active surface area for D-vehicles over the Artemis Motorway cycle increases by $40-430 \%$ depending on the fuel. The corresponding increases for PM were $22-190 \%$. This is achieved without any dramatic increase in the variability of the results.

The most significant increase of active surface over the Artemis Motorway is observed when D2 fuel is used, confirming that this is principally a sulfate issue. In particular, the highest emitting vehicle on D2 is a DPF equipped one while two more DPF vehicles reach the conventional Euro 3 levels.

Additionally, there is a general high spread of the emissions levels for DPF vehicles, even when using low sulfur fuel. This is because during different repetitions of the same cycle, the same vehicles operate either at normal mode or trap regeneration mode. There is a characteristic example where a DPF vehicle (Peugeot 406 measured at EMPA) shows a variable behavior, even using a low sulfur fuel (D4). Over four repetitions of the same cycle, the particular vehicle produced particles of surface area between 5.9 and $4170 \mathrm{~cm}^{2} / \mathrm{km}$. In parallel, its $\mathrm{CO}_{2}$ emissions ranged between 150 and $207 \mathrm{~g} / \mathrm{km}$ and its $\mathrm{CO}$ emissions between 0.017 and $0.47 \mathrm{~g} / \mathrm{km}$ respectively. There are no PM measurements available for the particular condition. The vehicle obviously operates on regeneration mode over the cycle repetition which leads to high emissions of particles and conventional pollutants. The same occurs for a vehicle measured in Shell (Peugeot 607) which emits between 7.6 and $54200 \mathrm{~cm}^{2} / \mathrm{km}$, depending on the mode of operation. On the other hand, the retrofitted vehicle at LAT (Renault Laguna) always maintains a consistent emission level of $100-200 \mathrm{~cm}^{2} / \mathrm{km}$ since it includes no active regeneration management and a dedicated protocol was applied to preserve low DPF backpressure.

In any case, the levels of particle surface area reached during regeneration remain below typical D-like levels.

Active Surface Summary - Active surface recorded with a diffusion charger reproduces the conclusions reached for PM emissions when conventional D-vehicles are concerned, confirming the relative levels of different emission standards and the effect of fuel and driving condition on emission levels. Active surface is in general more sensitive than PM without presenting a significant increase in the variability of results. 
DPF vehicles produce low levels of particle active surface when operating over the regulated NEDC and their emissions are at least one order of magnitude lower than D-vehicles, even using fuel with sulfur level at $300 \mathrm{ppm}$. Their emissions however become much more variable when a high power cycle is driven because regeneration mode conditions may be reached. Also, fuel sulfur effect was most obvious under high temperature operation (i.e. Artemis Motorway cycle). Under such conditions, DPF equipped vehicles on low sulfur fuels reduced active surface area by 3-4 orders of magnitude relative to the current case of Euro 3 vehicles and $300 \mathrm{ppm}$ sulfur fuels.

With regard to $G$ and DISI vehicles, conclusions from PM are also confirmed, in particular the individuality in vehicle behavior, the absence of consistent fuel effects and the possibility for diesel-like exhaust emissions from particular vehicles during high-power driving. Active surface emission levels spread over four orders of magnitude (compared to less than two for PM), allowing for a more clear comparison of the results.

\section{SOLID PARTICLE NUMBER}

Total concentration of "solid" particles is recorded with an Electrical Low Pressure Impactor (ELPI) which samples downstream of a thermodenuder (TD). "Solid" should be taken here as a convention for those particles not evaporated at TD temperatures up to $250^{\circ} \mathrm{C}$ and hence heavy semi-volatiles might also be included. We report here results collected over the first seven impactor stages, corresponding to aerodynamic diameters $30 \mathrm{~nm}$ $-1 \mu \mathrm{m}$. Results have been also corrected for solid particles losses in the TD. The absolute number concentration of the ELPI should be considered indicative because it also depends on the particle effective density [17] and no corrections have been performed for this. Although, correction for the effective density may change the absolute concentration of solid particles reported in the following sections, we decided not to do that at this stage but report emissions assuming unit $\left(1 \mathrm{~g} / \mathrm{cm}^{3}\right)$ particle density, as is common in all relevant diesel exhaust characterization studies.

Effect of vehicle technology - There are three individual ranges of particle number concentrations that can be distinguished in Figure 7. D-vehicles are generally found at over $10^{14}$ particles $/ \mathrm{km}$ with only two measurements clearly found below this threshold. There is a moderate variance of the emission levels, especially for fuels D2, D4 and D5 (for D4 the Ford Galaxy measured at EMPA was excluded as outlier) with COV values ranging between $20-30 \%$. Emissions with the D3 fuel appeared more variable mainly because of the measurements found below the threshold of $10^{14}$ particles $/ \mathrm{km}$. Additionally, there seems to be little influence of the vehicle emission standard with Euro 1 and 2 vehicles found within the range of the Euro 3 ones. Given the low PM levels of the particular vehicles though, it may not be deduced that this is a consistent effect of improving technology, as opposing evidence also exists [18].
DISIs are then found 10-20 times lower than D-vehicles, but still emit a significant number of solid particles.

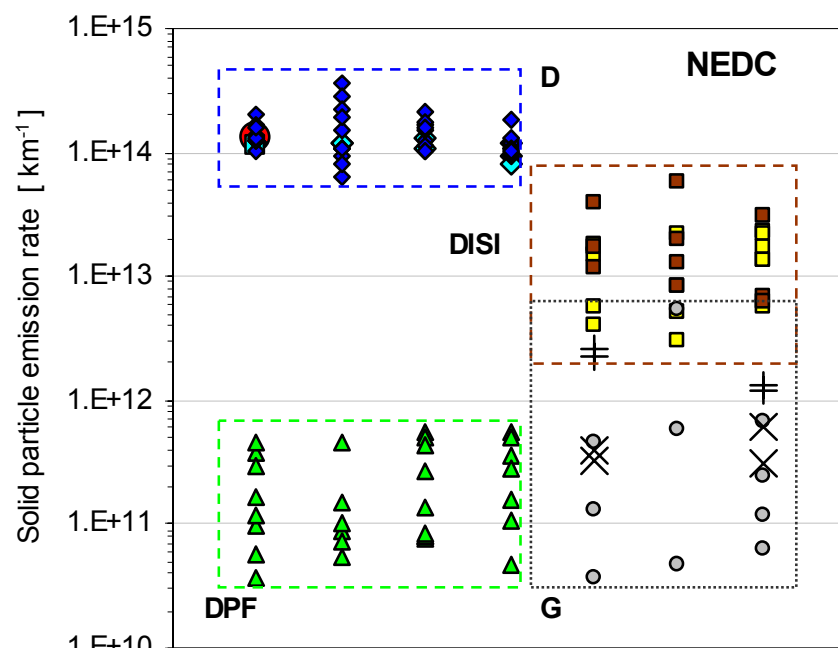

(a)
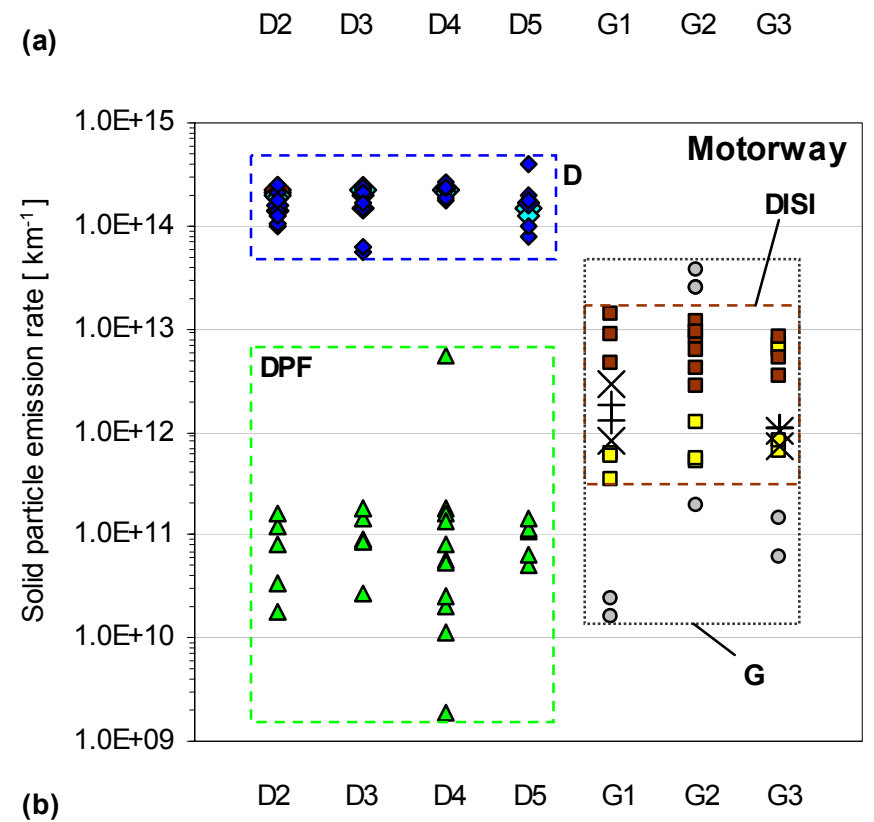

Figure 7: Integrated solid particle number emission rate over (a) NEDC and (b) Artemis Motorway cycles. Symbols as in legend of Figure 5.

There is an order of magnitude range for solid particle emissions from DPF vehicles. The real-time recordings of ELPI reveal that solid particles are mainly produced over the cold start portion of the cycle (Urban Driving Cycle - UDC). The mean particle flux over the UDC is $6.3 \times 10^{11}$ compared to $5.6 \times 10^{10}$ particles $/ \mathrm{km}$ over the extra urban part (EUDC). It is not clear where such solid particles come from because it is not reasonable to assume that the DPF efficiency decreases during cold start. The desorption of heavy semivolatile components which are not removed by the TD may be considered probable. 
Effect of fuel - There are no consistent effects of the D2D4 fuels on solid particle emissions of D-vehicles. However, there is a consistent reduction of the total particle number flux on a vehicle basis when using D5. The reduction in number ranges from $8 \%$ to $20 \%$, depending on the vehicle.

As one might expect, fuel effects on all other vehicle technologies are negligible, as a result of their lower emissions levels.

Effect of driving cycle - The effect of driving cycle on solid particle fluxes is insignificant and Artemis Motorway levels are found within $\pm 10 \%$ of the cold NEDC levels. Only in the case of D5 number flux seems to increase by $50 \%$ over cold NEDC. Therefore, if one wishes to obtain a reference solid number flux range of today's diesel cars over a cycle that would be $0.6-2 \times 10^{14}$ solid particles/km.

DPF-vehicles emit at or below the range of $10^{11}$ particles $/ \mathrm{km}$, over the Artemis Motorway cycle, at a level much below the NEDC, most probably due to the elimination of cold start. Only exception to the above is the case of the vehicle undergoing trap regeneration, where the emissions reach up $5.5 \times 10^{12}$ particles $/ \mathrm{km}$. This increase in particle number concentration is consistent to the one shown by Mohr et. al. [19].

Total solid particle number from DISI vehicles decreases in the Artemis Motorway by 3-4 times compared to the cold start NEDC. This is because solid particle number over the NEDC was 5-7 times higher over the cold start part, compared to the extra urban part and no cold start is included in the Motorway cycle. This may be attributed to over enrichment of the mixture during the cold start.

There is also a variable behavior from $\mathrm{G}$-vehicles. There is one particular vehicle (Alfa 146 measured at EMPA) where solid particle emissions reach up to $3.7 \times 10^{13}$ particles $/ \mathrm{km}$ over the Artemis Motorway. On the other hand, there are vehicles with moderate increases or even decreases over the NEDC (e.g. the Toyota Corolla at LAT emitted as low as $1.6 \times 10^{10}$ particles $/ \mathrm{km}$ ). These results demonstrate that there is no typical effect of the driving cycle on conventional gasoline vehicles but their performance is specific to the engine management details. In any case, their (mainly off-cycle) solid particle emissions may become significant in the future as DPF-vehicles become common and replace the conventional diesel vehicles.

Solid Particle Summary - Solid particle emission rates from D-vehicles are fairly constant with emissions less influenced by driving cycle and fuel use, compared to PM. For the limited sample of older vehicles studied, no consistent effect of emission standard could either be revealed. Therefore, solid particle number concentration is rather vehicle specific and is found in the range of 0.6$2.0 \times 10^{14}$ particles $/ \mathrm{km}$.
As with DC, ELPI offers potential advantage in sensitivity and discrimination versus the PM mass method. Nevertheless, conclusions on vehicle technology effects are similar to those for PM mass.

DPF-vehicle emissions are at least two orders of magnitude lower than conventional D-vehicles over the regulated cycle, with emissions mainly occurring during the cold start part of the cycle. There was no effect of fuel on these emissions. However, similar to active surface, emissions may increase over high-power driving, when regeneration is initiated. Still, under such conditions, solid particles emission rate remains $40-50$ times below D-levels.

DISI vehicles emit 10-20 times lower rates of solid particle emissions than D-vehicles over all driving conditions and show little preference to fuel properties. Their emission level over the high-power cycle reduces compared to the regulated NEDC due to the absence of a cold-start part.

G-vehicles show the most variable behavior, mainly due to individuality in their performance. Their solid particle emission levels are at equal range with DPF-vehicles over the regulated cycle and, generally, one to two orders of magnitude below DISI. However, during high power driving, there are cases which approach D-like levels. Such behavior is clearly vehicle specific.

\section{TOTAL PARTICLE NUMBER}

Effect of vehicle technology - Total particle (CPC) emissions of D-vehicles over the regulated NEDC when low sulfur fuels are used, range from 0.6$2 \times 10^{14}$ particles $/ \mathrm{km}$; the same range recorded with the ELPI for solid particles (not applying effective density corrections). Obviously, CPC and ELPI levels between vehicles are within this range but may present individual inconsistencies. In any case, establishing the same levels between solid and total particles suggests that despite using a sampling system that favors volatile particle formation, there is no particular nucleation mode formed over the regulated cycle for the Euro 3 vehicles examined. Additionally, total number concentration seems to be little varying for D-vehicles using low sulfur fuel. Coefficient of variance for the measurements in all labs and all vehicles is $30 \%$ with a decrease to $19 \%$ for the D5 fuel. The same figures for PM were $21 \%$ and $20 \%$ respectively. Therefore, similar to solid particle number, the measurement of total particle number over a transient test, using a dedicated protocol and sampling setup does not seem exceptionally prone to artifacts or errors.

DISI vehicles are also found at the same levels with their solid particle distributions, in the range of $10^{13}$ particles $/ \mathrm{km}$. However they are less differentiated with G-vehicles which emit $5-10$ times more volatile particles than solid ones. Comparing total particle number concentration of G-vehicles during transient performance with emission levels over steady states 
reveals that such particles are mainly formed during transients.
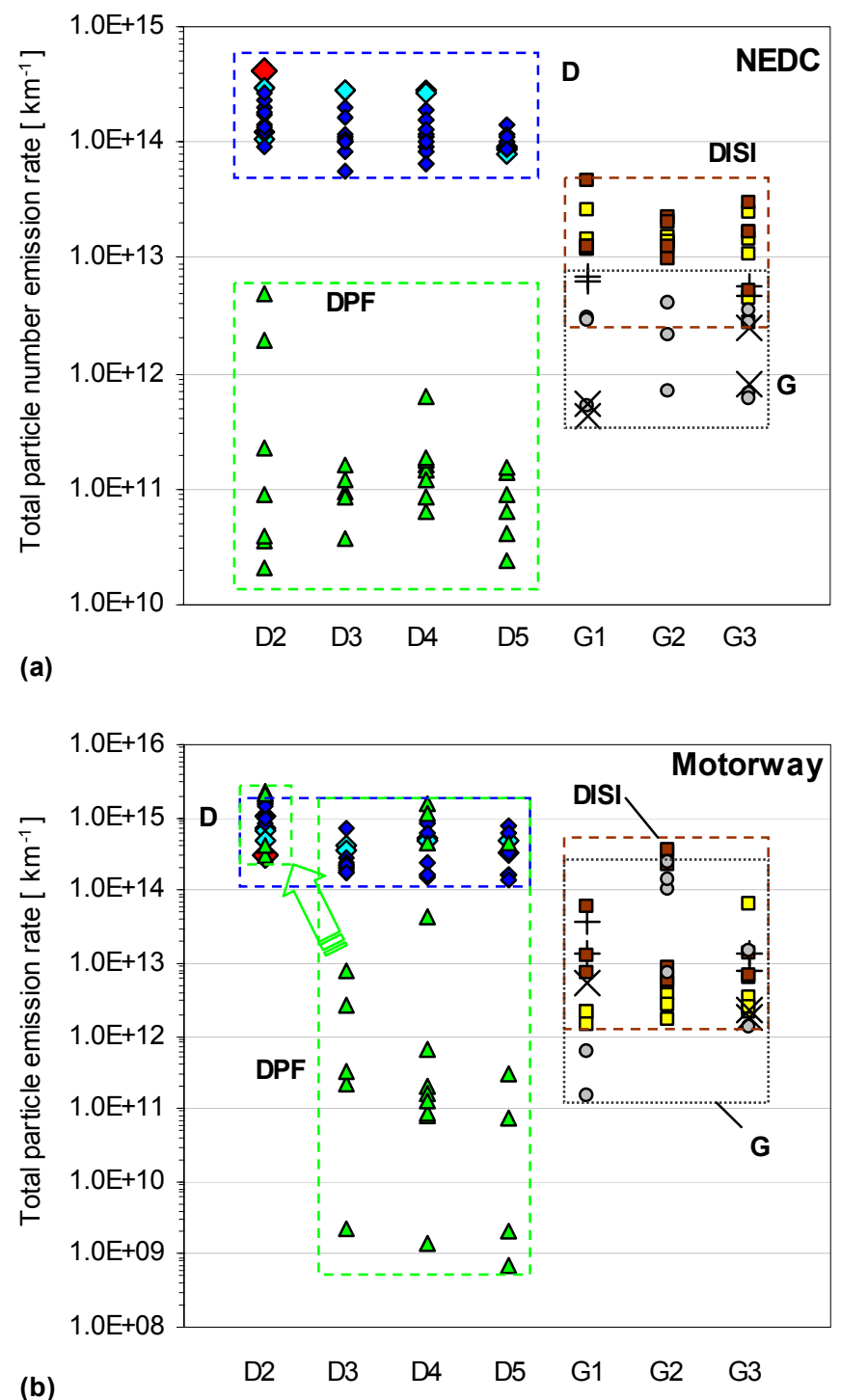

Figure 8: Integrated total particle number emission rate over (a) NEDC and (b) Artemis Motorway cycles. Symbols as in legend of Figure 5.

The lowest emission level is recorded for DPF-vehicles, operating on low sulfur fuel which may emit more than one order of magnitude below even the cleanest of gasoline vehicles and some 3-4 orders of magnitude below conventional diesel vehicles on current $300 \mathrm{ppm} \mathrm{S}$ fuels. Actually, the highest emitting DPF-vehicle is found at the same level of the lowest emitting G-one.

Effect of fuel - There is an increase of particle number concentration when D2 fuel is used over the regulated cycle for Euro 3 D-vehicles (60-70\% higher compared to D3-D5 fuels). This increase is consistent for all sample vehicles. In the same manner, there are two cases where DPF emissions exceed $10^{12}$ particles $/ \mathrm{km}$ when using fuel of higher sulfur content (D2). As in the previous cases, the effect of fuel is overall negligible for G-vehicles and DISI.

Effect of driving cycle - Similar to the recordings of active surface, the effect of driving cycle is also dependent on the fuel used. When low sulfur fuel is used (D3-D5), emissions of Euro 3 D-vehicles increase by 3 times compared to NEDC levels. Also, comparison of ELPI and CPC recordings over the Artemis Motorway shows that average total particle emissions are $60 \%$ higher than solid particles. These are indications that there is a minor formation of volatile particles over the demanding Artemis cycle.

The increase in particle emission rate is more significant when D2 fuel is used and particle emissions of Euro 3 Dvehicles may exceed $10^{15}$ particles $/ \mathrm{km}$. On the other hand, the Euro 1 vehicle with its catalyst removed appears now as the lowest emitter with this fuel, remaining at a level of $4 \times 10^{14}$ particles $/ \mathrm{km}$. These are obviously results of sulfate particle formation as the oxidation catalysts heat up during this cycle.

Nucleation mode formation is dramatic for DPF vehicles, using the D2 fuel. Trap-fitted vehicles reach and even exceed the total emission rate from conventional diesel vehicles. Such high levels are also encountered with the regenerating trap system of the Peugeot 406 vehicle operating on D4. However, DPF systems operating on low sulfur fuel and over a non-regeneration phase may still remain at or below $10^{11}$ particles $/ \mathrm{km}$ levels. As a summary, driving cycle effects on total number emission rate of DPF vehicles are very important and result in variation of the average emission level of such vehicles within 6 orders of magnitudes.

The performance of $G$ and DISI vehicles over a high power cycle is vehicle specific with regard to their total particle emission rate. However, one should point out that there are vehicles that may reach or even exceed diesel-like emission levels, by increasing their emission levels by more than two orders of magnitude compared to the cold NEDC. Possible mechanisms are obviously over-enrichment to increase drivability and power output in such off-cycle conditions.

Total Particle Summary - Total particle number emission rates recorded for D-vehicles over the regulated cycle, using a dedicated sampling procedure are found within a narrow range and do not seem particularly prone to artifacts, as previously published evidence suggests. Additionally, total and solid number concentrations determined with different techniques seem to be at similar levels for the different vehicles. When high power cycles are involved, total particle emissions increase by 2-7 times, depending on the sulfur content of the fuel. In each case, the measurement of total number of particles over transient tests for passenger cars seems to be sufficiently robust, able to fully reproduce expected effects. 
Over the regulated cycle, trap equipped diesels on low sulfur fuels give massive emissions reductions versus the current non-DPF, current $300 \mathrm{ppm} S$ fuel case. In fact, DPF vehicles correspond to the lowest particle number emitters from all vehicle technologies examined, especially for low sulfur fuels. The cleanest gasoline vehicle measured corresponds to the dirtiest of DPFvehicles operating on low sulfur. It was also found that passenger cars of all technologies (including DPF fitted cars), despite the usage of a sampling system favoring volatile particle formation, do not produce any dramatic concentration of nucleation mode over the regulated cycle.

However, when DPF-vehicles operate on high sulfur fuel, there is a large formation of nucleation mode over high power cycles. In this particular case, it is observed that a DPF vehicle produced the highest and the older Euro 1 vehicle the lowest particle number respectively of all vehicles in the diesel sample. Additionally, filter regeneration mode may lead to high particle number concentration, even when using low sulfur fuels.

Finally, it appears that high power driving conditions may lead to diesel-like particle number of $G$ and DISI vehicles. This may require further control of particle emissions from such vehicles as DPF-vehicles become increasingly common.

\section{PARTICLE SIZE DISTRIBUTIONS}

SMPS Distributions - Information on the size of total particles emitted can be given with SMPS distributions obtained in steady states. Figures 9 and 10 present particle size distributions from diesel and gasoline cars respectively, discriminated between D, DPF and G, DISI respectively. Two speeds are considered $(50 \mathrm{~km} / \mathrm{h}$ and $120 \mathrm{~km} / \mathrm{h}$ ) in order to demonstrate the effect of speed on emissions.

With regard to diesel vehicles at $50 \mathrm{~km} / \mathrm{h}$, there is a lognormal distribution established for all conventional $D$ vehicles. Geometric mean $\left(\mathrm{d}_{\mathrm{g}}\right)$ diameters are in the range of $65-70 \mathrm{~nm}$ and decrease slightly using D5 fuel $(62 \mathrm{~nm})$. DPF vehicles seem to form a cloud rather than actual distributions, an indication of the very low particle concentration downstream of a particle trap and low speed driving.

At $120 \mathrm{~km} / \mathrm{h}$ there is nucleation mode formed for some of the $D$ and DPF vehicles, especially with fuels of higher sulfur content. There is one vehicle (VW Golf measured at IFP) which presents nucleation mode even using fuel D5. Peaks for the nucleation mode appear at the 20$50 \mathrm{~nm}$ range for conventional D-vehicles. DPF-vehicles produce a nucleation mode peak at $10-20 \mathrm{~nm}$ when using fuel with sulfur content down to $38 \mathrm{ppm}$. However, the nucleation mode becomes less significant as sulfur level decreases.

There is a less clear picture with regard to the total particle size distributions from gasoline fueled vehicles, which confirm that the behavior of such vehicles is typespecific and may change significantly depending on sampling conditions. At $50 \mathrm{~km} / \mathrm{h}$ one may establish a rather diesel like accumulation mode, at smaller particle sizes though $\left(d_{g}=36-45 \mathrm{~nm}\right)$, for DISI vehicles. There are cases of DISI-vehicles with more than one order of magnitude difference in their emission levels. G-vehicles distribution profile is also variable with some cases only forming a cloud of values and some other vehicles forming a low but measurable accumulation mode.
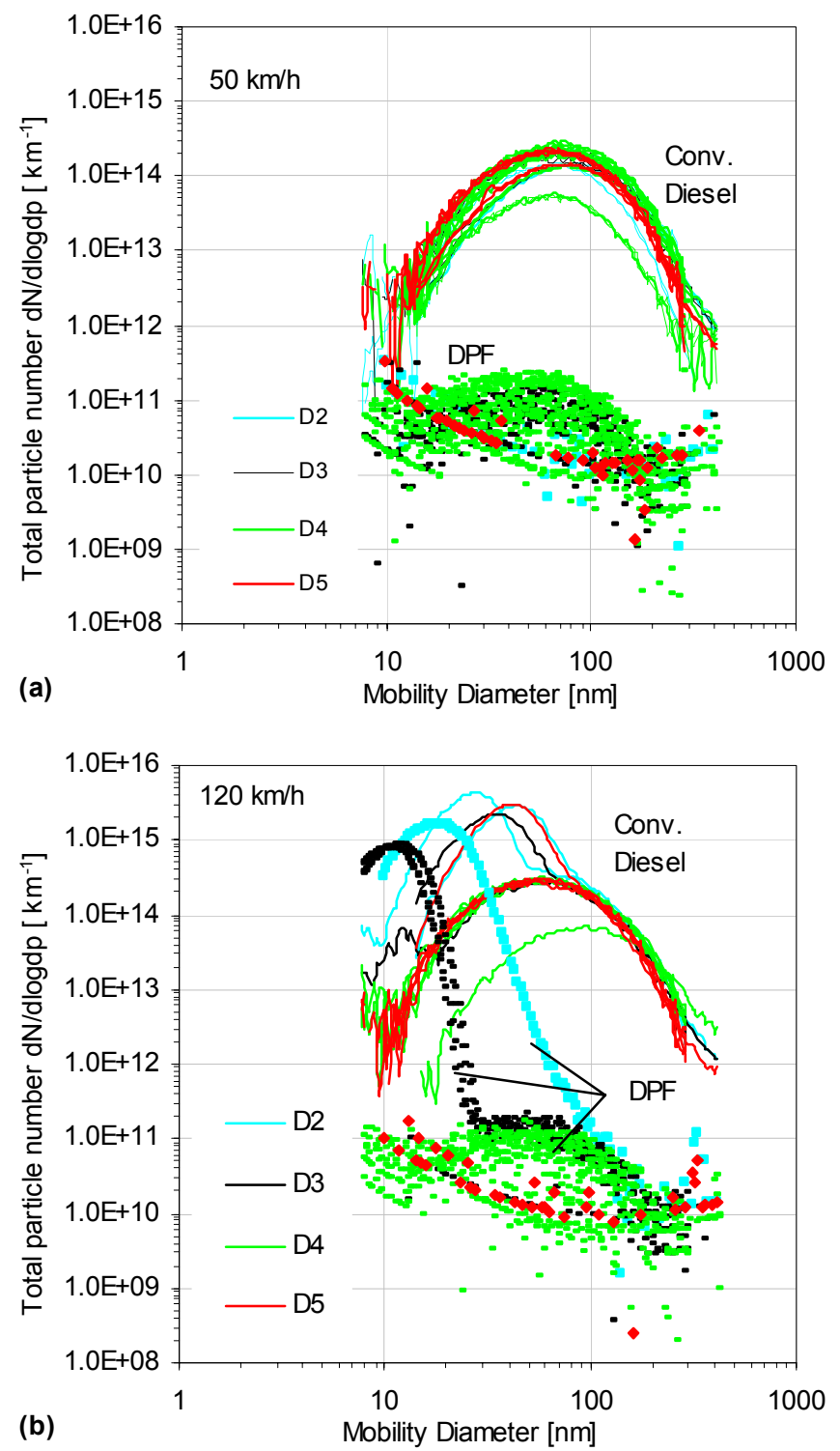

Figure 9: SMPS distributions of conventional diesel and DPF vehicles over (a) $50 \mathrm{~km} / \mathrm{h}$ and (b) $120 \mathrm{~km} / \mathrm{h}$.

At $120 \mathrm{~km} / \mathrm{h}$ there are several patterns observed, depending on the vehicle examined. DISI vehicles continue to form an accumulation mode with mean diameters $\left(d_{g}\right)$ that can reach up to $68 \mathrm{~nm}$. Again, the level of the distribution is variable. On the other hand, Gvehicles show a vehicle-dependent emission behavior. Some of the vehicles remain at background 
concentration, one forms a distinct accumulation mode with a peak at $\sim 70 \mathrm{~nm}$ and one produces a nucleation mode at sub- $20 \mathrm{~nm}$ diameters. There are several parameters which may be responsible for this variable behavior in G-vehicles, including mainly the lambdavalue control and the associated over-enrichment and the catalyst temperature and storage-release properties.
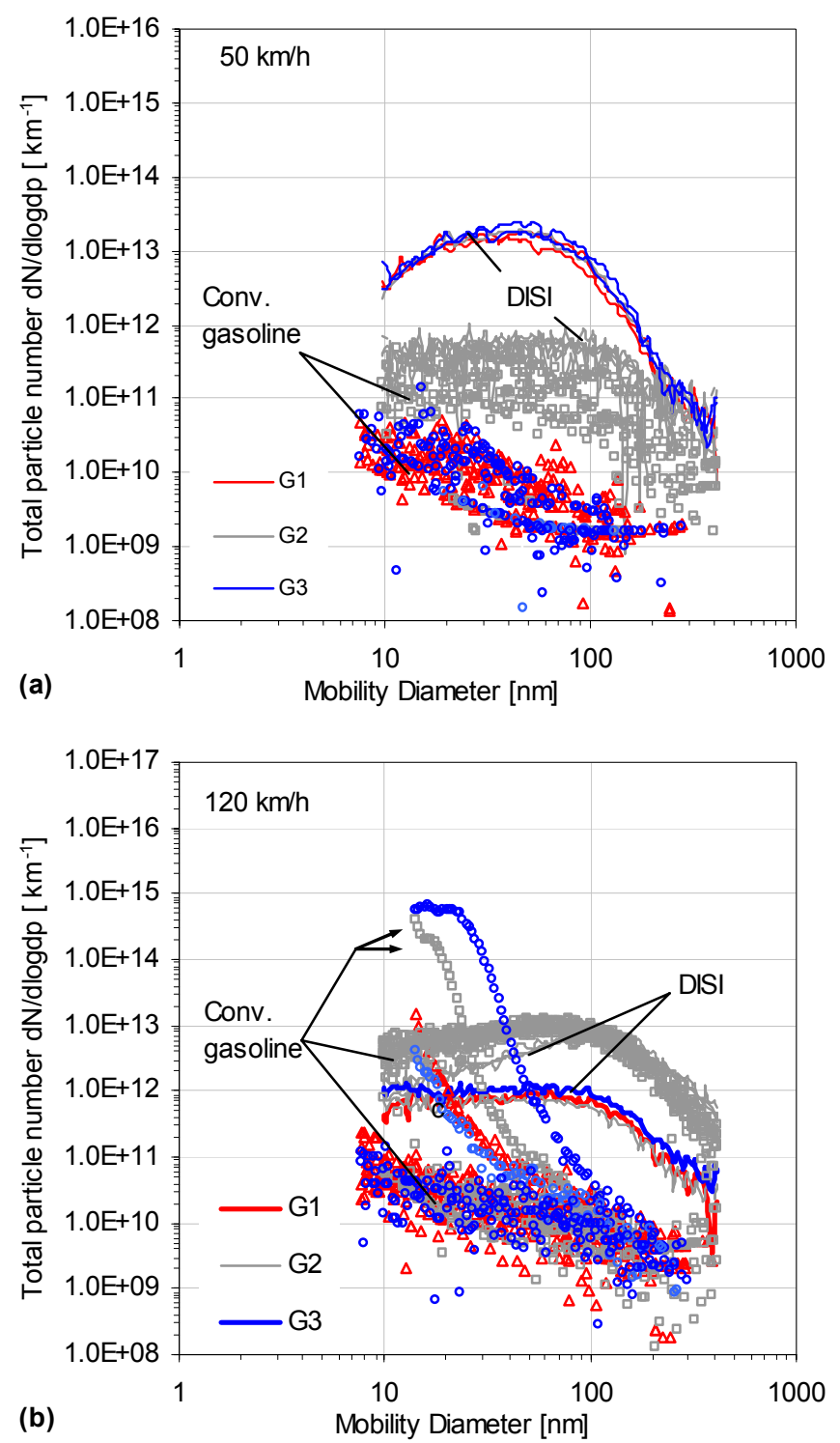

Figure 10: SMPS distributions of conventional gasoline and DISI Euro 3 vehicles over (a) $50 \mathrm{~km} / \mathrm{h}$ and (b) $120 \mathrm{~km} / \mathrm{h}$.

As a summary of SMPS distributions, one may observe that for diesel vehicles there is a significant effect of the driving condition and sulfur content on emissions, with a distinct nucleation mode appearing for the higher sulfur fuel at high speed driving. This picture seems typical for both conventional and DPF fitted vehicles. For gasoline vehicles it is not possible to draw any general conclusions. However, cases have been identified where gasoline vehicles may emit significant total numbers of particles both in the accumulation and in the nucleation mode. These are situations that one might need to better control in the future.

ELPI Distributions - Figures 11 and 12 present the ELPI distributions of solid particles collected for all vehicle categories and all fuels examined in this paper. We found out that there is no significant information that may be obtained by classifying distributions on a per fuel basis (further to a per vehicle reduction when using D5 fuel). Therefore all distributions are shown as areas that include all vehicles and fuels. Charts are plotted using the geometric mean sizes of the impactor stages cutpoints in the abscissa.

Distributions from $D$-vehicles are similar over both cycles examined showing a peak at $60-65 \mathrm{~nm}$ over the cold NEDC and $72-78 \mathrm{~nm}$ over the Artemis Motorway (63 nm with D5). DPF distributions are D-like over the cold NEDC $\left(d_{g}=58-65 \mathrm{~nm}\right)$ but at levels 2-3 orders of magnitude lower than conventional $\mathrm{D}$-vehicles. The distributions become more flat over the Artemis Motorway due to the absence of a cold-start. There is one particular case though that corresponds to the vehicles operating on DPF-regeneration mode over the cycle. This presents a significant accumulation mode shifted to small sizes $\left(d_{g}=47 \mathrm{~nm}\right)$.

$G$ and DISI vehicles confirm their individual behavior also when looking solid particle distributions. There is a discrimination between the two vehicle technologies over the regulated NEDC, with DISI distribution significantly higher and with geometric mean diameters $(\mathrm{dg})$ in the order of $72-77 \mathrm{~nm}$. Distributions of G-vehicles spread over almost three orders of magnitude for the same particle size while mean diameters are found in the 52$66 \mathrm{~nm}$ range. When moving to Artemis Motorway, the picture is partly reversed with G-vehicles even exceeding the concentration of DISI ones for small particle sizes but still spreading over several orders of magnitude.

Summarizing, solid particle distributions only confirm findings discussed in the previous sections: First, the small impact of fuel on the concentration is also extended to the size distribution. The effect of the DPF in filtering solid particles appears over the whole size range studied. During regeneration of one particular vehicle though, small solid or semi-volatile particle emissions increase significantly. Gasoline vehicles behavior is largely dependant on driving condition but there is no solid nuclei peak as observed for total particles. However, still significant numbers of small solid particles seem to be emitted under high speed driving. 

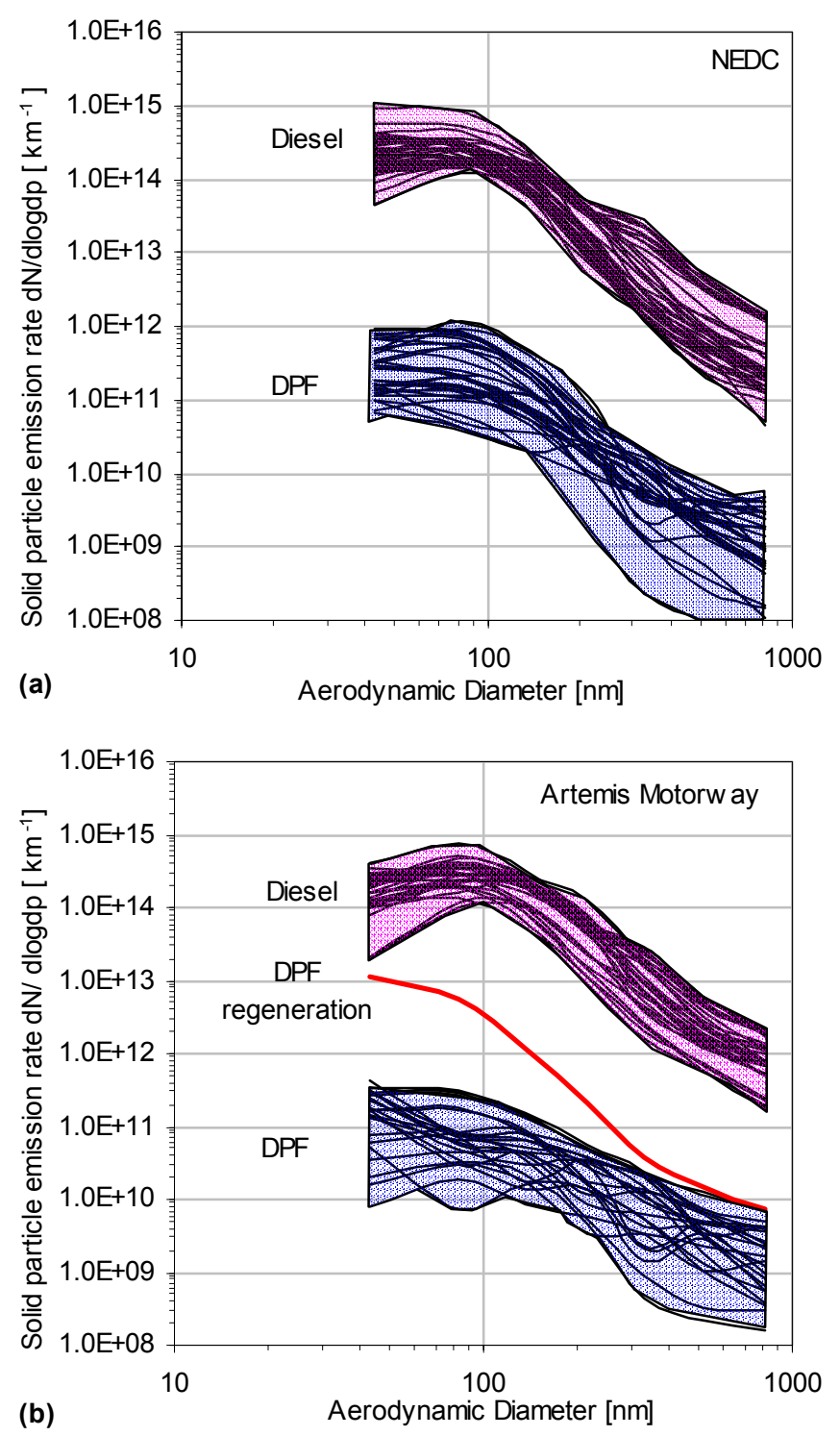

Figure 11: Solid particle size distributions of conventional diesel Euro 3 and DPF vehicles recorded with the ELPI over (a) the NEDC and (b) Artemis Motorway cycles.

\section{INSTRUMENT CORRELATIONS}

Figure 13 shows the correlation of four different particle properties (determined with the partial flow sampling system) with the regulated PM mass (determined with the CVS procedure). Results have been collected for the four groups of vehicles and correspond only to Euro 3 technology (including those diesel vehicles fitted with DPFs). Depending on the instrument, 250-420 individual measurements are plotted in each chart corresponding to five different cycles: the NEDC starting from cold and hot operation and the three hot start Artemis cycles (Figure 1). In each chart the $5^{\text {th }}$ and $95^{\text {th }}$ percentile lines have been also plotted to provide a broad correlation between the associated properties.
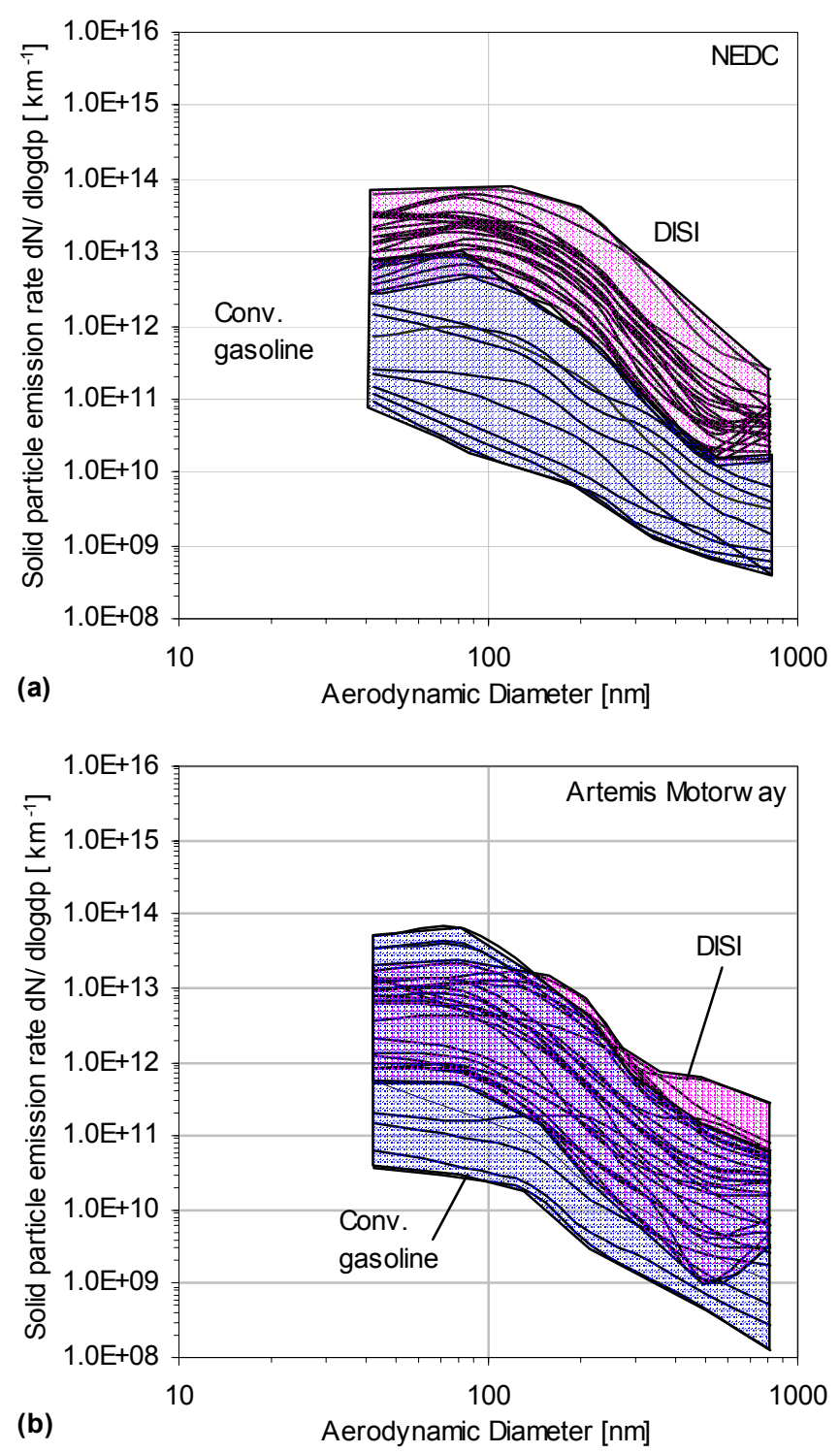

Figure 12: Solid particle size distributions of conventional gasoline and DISI Euro 3 vehicles recorded with the ELPI over (a) the NEDC and (b) Artemis Motorway cycles.

Gravimetric Impactor - The first correlation corresponds to the total mass collected in the gravimetric impactor (DGI), sampling from the partial flow sampling system, with PM from the CVS. Since the impactor draws from a varying flowrate exhaust stream with a constant flowrate sampling system, the total integrated mass collected in the impactor cannot equal the mass collected with the CVS filter. This is not a problem for the DGI over steady states (constant exhaust flowrate) or for real-time instruments (where real-time exhaust flowrate is taken onto account). Also, there are different temperature and dilution conditions established in the CVS compared with the gravimetric impactor position. However, this correlation is useful to provide a general check of the partial flow sampling system in comparison to the CVS regulated procedure. 

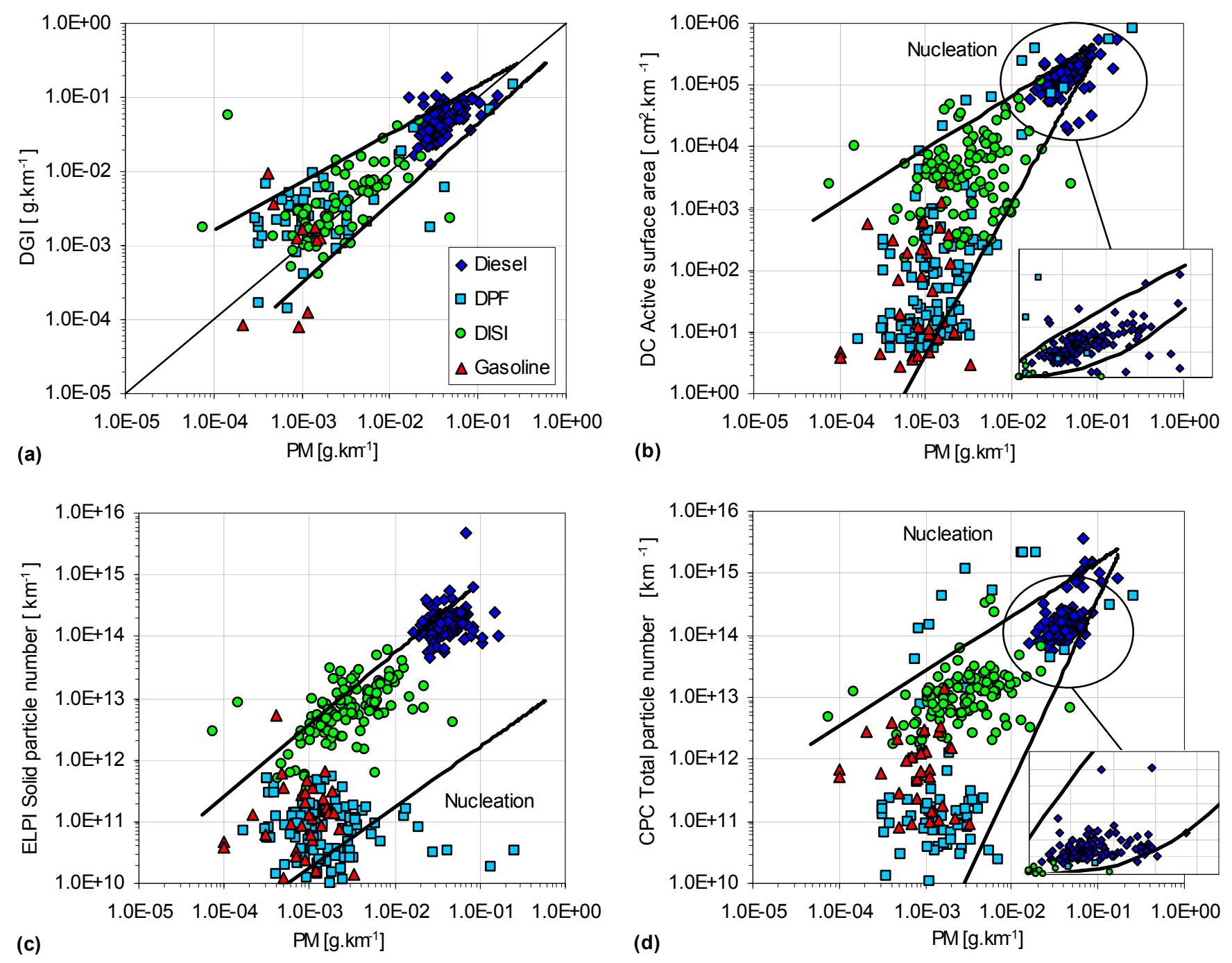

Figure 13: Correlation of different particle properties with the regulated PM procedure. Emissions collected over the NEDC cycles (cold and hot start) and the three Artemis Cycles. (a) Total mass in gravimetric impactor, (b) Active surface from the diffusion charger, (c) Total solid particle number from the ELPI, (d) Total particle number from the CPC. "Nucleation" designates the side of the correlation where nucleation mode should become visible.

This comparison shows that there is a fairly good agreement between the two methods for conventional diesel vehicles, where emission levels are above $10 \mathrm{mg} / \mathrm{km}$, with $95 \%$ of the DGI measurements found between $\pm 50 \%$ of the CVS PM mass. The correlation below that point becomes weaker either because the sensitivity of the measurements is limited or because there is a stronger potential for condensation at the DGI position, especially for DPF-vehicles. At $1 \mathrm{mg} / \mathrm{km} \mathrm{PM}$ there is an order of magnitude range for $95 \%$ of the DGI results.

Active surface area - Comparison of Figures 5 and 6 showed that active surface and PM may provide similar conclusions but the DC was deemed as a more sensitive method. Indeed, this is also shown in Figure 13b, despite that there is not a very good correlation of the two methods over the whole range of vehicle technologies. There is a very narrow band of the $5^{\text {th }}$ $95^{\text {th }}$ percentile lines for diesel vehicles and a good discrimination of the different vehicle technologies. The inset zooms in the D-vehicles region (on a linear scale) where it shows that active surface and PM are sufficiently correlated. However, at low PM concentrations $(\sim 1 \mathrm{mg} / \mathrm{km})$, corresponding active surface values range over more than three orders of magnitude and a lower limit of the method seems to be reached at $10 \mathrm{~cm}^{2} / \mathrm{km}$. This clearly shows that DC is much more sensitive than gravimetric PM at these low mass levels.

Solid particle number - There is a totally different picture seen for the correlation of total solid particle number (ELPI and TD) concentration with PM. Figure 13c practically shows that there is no correlation between solid particle counts and PM and this is mainly due to the DPF-vehicles showing high PM mass and negligible 
particle counts when nucleation occurs with high sulfur fuels. However, it appears that there are three distinct regions formed (D, DISI and G together with DPF) and a visible correlation is only established for DISI vehicles. All other vehicle technologies just form a cloud of values at different absolute levels.

Total particle number - There is also a weak correlation between total particle number (CPC) and PM which improves when trying to establish a correlation over all vehicle technologies rather than correlation within one technology. Especially the inset shows that there is no correlation between CPC and PM values of conventional $D$-vehicles, in contrast to the active surface values. Additionally, the effect of nucleation mode is obvious with such cases exceeding the $95^{\text {th }}$ percentile line by as much as an order of magnitude. Due to this, total particle number concentration cannot be used to discriminate the individual vehicle technologies as effectively as solid particle concentration.

Instruments correlation summary - The total mass collected in the gravimetric impactor at the partial flow sampling system is in satisfactory agreement to the CVS results, despite the different sampling procedure. This is a good indication of appropriate operation of the sampling system (aspiration efficiency) and a proper cross-check for the calculation procedure (measurement of exhaust flowrate, determination of dilution ratios, etc.). All measurements of airborne aerosol samples are significantly more sensitive than the reference gravimetric procedure with airborne emissions spreading over five orders of magnitude compared to less than three for gravimetric measurements.

Taking the gravimetric procedure as the reference for diesel vehicle particle emissions, where emissions levels are at least measurable, it is shown that active surface is satisfactorily correlated with PM while the numbers of solid and total particles are not at all correlated. It is not possible to draw any conclusions for correlation at lower than diesel emission levels, also due to the limited sensitivity of the gravimetric procedure. On the other hand, use of the solid particle number as an indication of particle emissions may provide a clear discrimination of vehicle technologies (D, DISI and $G$ and DPF at the same levels). Finally, total particle number is largely dominated from the appearance of nucleation mode and as such can give little information on the characteristics of different vehicle technologies.

\section{SUMMARY AND CONCLUSIONS}

A new measurement protocol, developed specifically for testing over transient cycles, has been successfully employed in several labs to evaluate a wide range of particulate properties with a range of light duty vehicles and fuels. The measured properties included particle number, with particular focus on nucleation and accumulation modes, particle active surface and particle mass-based distributions, in addition to the current total mass. The vehicle sample consisted of 22 cars, including conventional diesels, DPF equipped diesels, port fuel injected and direct injection SI cars. Four diesel and three gasoline fuels were used, mainly differentiated with respect to their $S$ content which was ranging from 300 to below $10 \mathrm{mg} / \mathrm{kg}$.

On the basis of the data presented in this paper the following conclusions can be drawn:

\section{A. Results over the regulated cycle}

Conventional Euro 2 and Euro 3 diesel vehicles are associated with PM mass emissions complying with the Euro 3 emission limit, and are generally not affected by fuel sulfur content. Similarly, both their active surface area and solid particle number concentrations were found in a relatively narrow range, irrespective of fuel sulfur $\left(10^{5} \mathrm{~cm}^{2} / \mathrm{km}\right.$ and $0.6-2.0 \times 10^{14}$ particles $/ \mathrm{km}$ respectively). However, it needs to be stressed that both active surface and solid particles concentration were also found to be in general more sensitive than mass, without presenting a significant increase in the variability of results. Interestingly, total particle number emissions (i.e. including nucleation mode particles) over the regulated cycle were also found within a narrow range (0.6$2.0 \times 10^{14}$ particles $/ \mathrm{km}$, i.e. identical to solid number emission) and did not seem particularly prone to artifacts, in contrast to what earlier experience may have shown. This suggests that the usage of a dedicated sampling procedure is in the position to yield sufficiently repeatable results for both solid and total particle populations.

Trap equipped diesels are associated with massive reductions of particle emissions with respect to their conventional diesel counterparts, irrespective of the property used to characterize them. These reductions ranged from one order of magnitude in terms of mass, to 1 to 3 orders of magnitude in terms of surface area, 3 orders of magnitude in terms of solid particles and 2 to 4 orders of magnitude in terms of total population. There is evidence of influence of higher fuel sulfur content $(300 \mathrm{mg} / \mathrm{kg}$ ) on nucleation mode particles (captured by active surface and total number concentration), basically associated with the cold start part of the cycle. Finally it has to be noted that DPF vehicles are found to be the lowest total particle number emitters from all vehicle technologies examined, especially for low sulfur fuels.

Over the regulated cycle, DISI's give measurable mass emissions, though well below diesel Euro 4 limit, an issue that needs to be addressed with respect to Euro 5 . Active surface area, solid particle numbers and total particle numbers reveal a similar behavior of DISI vehicles, with higher sensitivity though than the mass measurements. No consistent fuel effects were revealed.

The conventional (port injected) gasoline vehicles were found to be emitting at or below the levels of DPF equipped diesels, one or two orders of magnitude below the DISI counterparts, and this for all particle parameters tested. Their emissions performance was found to be 
variable, strongly depending on the characteristics of the engine management of the particular vehicle, and very little affected by fuel sulfur.

\section{B. Results over high power driving cycles}

Driving over a high power, high temperature cycle unveiled some particular characteristics of the emissions behavior of the different vehicle technologies in conjunction with the fuel sulfur content.

High power driving may lead to an up to one order of magnitude increase in particle emissions, and generally much more variable emissions behavior, irrespective of the property used to characterize them. Only exception to this general observation was the solid particle number emissions of conventional diesel cars, which were found insensitive to driving cycle.

The above mentioned particle emission increase was generally more pronounced in the case DPF equipped vehicles operated on the higher sulfur fuel $(300 \mathrm{mg} / \mathrm{kg})$. In this case these vehicles were found to reach the emission levels of conventional diesels, in terms of mass, active surface and total number emissions. This particular behavior of DPF cars is related with the regeneration attempts, which are likely to be initiated during the high temperature operation over this cycle. Again exception to this behavior was the concentration of solid particles which, despite their increase, were found below conventional diesel levels.

Gasoline vehicles (both conventional and DISI) were found to be associated with a possibility for diesel-like exhaust emission levels during high-power driving, in terms of mass, active surface and total particle numbers. However, this possibility is related with particular vehicles, a fact which again reveals the individuality in vehicle behavior and the absence of consistent fuel effects. Sole exception is again the case of solid particles of DISI vehicles, which were found to emit less compared to the regulated NEDC due to the absence of a cold-start part.

In summary, with respect to diesel cars a significant effect of the driving condition and sulfur content on emissions was found, with a distinct nucleation mode appearing with the higher sulfur fuel at high speed driving. This picture seems typical for both conventional and DPF fitted vehicles. With gasoline vehicles it is not possible to draw any general conclusions. However, cases have been identified where gasoline vehicles may emit significant total numbers of particles both in the accumulation and in the nucleation mode. These are situations that one might need to better control in the future.

It is hopped that the results of this work can contribute to the development of a common basis for understanding with respect to the measurement procedures of particles and the evaluation of emission controls. In this context, it is made clear that DPF equipped diesel vehicles operating on sulfur-free fuels can approach levels of particulate emissions comparable to conventional gasoline vehicles and that DI gasoline vehicles need to be separately addressed. Evidently, there are still remaining issues that may attract contrasting argumentation, such as the excessively discussed but not fully understood "nucleation mode" and the impact of sampling procedure on emissions. Despite such obstacles, steps already started to be taken towards the extension of vehicle particulate emissions legislation beyond particulate mass [20].

\section{ACKNOWLEDGMENTS}

This work has been conducted in the framework of the EC DG TREN "PARTICULATES" project (Contract No. 2000-RD.11091). The authors would like to thank all partners for a constructive collaboration and significant contribution in all stages of the project development.

\section{REFERENCES}

1. CONCAWE 1998. A study of the number, size \& mass of exhaust particles emitted from European diesel and gasoline vehicles under steady-state and European driving cycle conditions. Report no. 98/51, Brussels, Belgium.

2. Marjamäki, M.; Keskinen, J. 2001. Vehicle exhaust particulates characterization, properties, instrumentation and sampling requirements. Deliverable 2 of the "Particulates" project, Internet ref. at http://vergina.eng.auth.gr/mech/lat/particulates

3. Ntziachristos, L.; Giechaskiel, B.; Pistikopoulos, P.; Samaras, Z.; Mathis, U.; Mohr, M.; Ristimäki, J.; Keskinen, J.; Mikkanen, P.; Casati, R.; Scheer, V.; Vogt, R. 2004. Performance evaluation of a novel sampling and measurement system for exhaust particle characterization. SAE Paper 2004-01-1439.

4. Andersson, J.D.; Wedekind, B.G.A.; Hall, D. 2000. DETR/SMMT/CONCAWE Particle Research Programme: Sampling and Measurement Experiences. SAE Paper 2000-01-2850.

5. Wedekind, B.G.A; Andersson, J.D.; Hall, D.; Stradling, R.; Barnes, C.; Wilson, G. 2000. DETR/SMMT/CONCAWE Particle Research Programme: Heavy Duty Results. SAE Paper 200001-2851.

6. Andersson, J.D.; Wedekind, B.G.A.; Hall, D.; Stradling, R.; Wilson, G. 2001. DETR/SMMT/CONCAWE Particle Research Programme: Light Duty Results. SAE Paper 200101-3577.

7. Kittelson, D.; Watts, W.; Johnson, J. 2002. Diesel Aerosol Sampling Methodology, Final Report CRC E43, University of Minnesota, 8/19/2002.

8. ACEA 1999. ACEA Programme on Emissions of Fine Particles from Passenger Cars, December 1999, Brussels, Belgium. 
9. ACEA 2002. ACEA Programme on Emissions of Fine Particles from Passenger Cars [2], July 2002, Brussels, Belgium.

10. UNECE 2001. Programme Overview: GRPE Particle Measurement Programme. UNECE WP29/GRPE Group, GRPE 42 ${ }^{\text {nd }}, 29$ May - 1 June 2001.

11. European Parliament and Council, 2003. Directive 2003/17/EC of the European Parliament and of the Council of 3 March 2003 amending Directive 98/70/EC relating to the quality of petrol and diesel fuels, Official Journal, L 076, pp. 0010-0019.

12. European Parliament and Council, 1998. Directive 98/69/EC relating to measures to be taken against air pollution by emissions from motor vehicles and amending Council Directive 70/220/EEC, Official Journal, L 350, pp. 0001-0057.

13. ARTEMIS 2003. Assessment and Reliability of Transport Emission Models and Inventory Systems, European Commission, DG Transport and Energy, Internet reference at http://www.trl.co.uk/artemis/

14. Maricq, M.M.; Podsiadlik, D.H.; Brehob, D.D.; Haghgooie, M. 1999. Particulate Emissions from a Direct-Injection Spark-Ignition (DISI) Engine. SAE Paper 1999-01-1530.

15. Chase, R.J.; Duszkiewicz, G.J.; Richert, J.F.O.; Lewis, D.; Maricq, M.M; Xu, N. 2004. PM Measurement Artifact: Organic Vapor Deposition on Different Filter Media. SAE Paper 2004-01-0967.

16. ACEA and EUROPIA, 1996. European Programme on Emissions, Fuels and Engine Technologies (EPEFE). Final Report, Brussels, Belgium.

17. Ristimäki, J.; Virtanen, A.; Marjamäki, M.; Rostedt, A.; Keskinen, J. 2002. On-line measurement of size distribution and effective density of submicron aerosol particles, Journal of Aerosol Science, Vol. 33, pp. 1541-1557.

18. Ntziachristos, L.; Samaras, Z. 2003. New Directions: Emerging Demands for Vehicle Particle Emission Characterisation. Atmospheric Environment, Vol. 37, pp. 441-442.

19. Mohr, M.; Lehmann, U.; Margaria, G. 2003. ACEA Programme on the Emissions of Fine Particulates from Passenger Cars (2) Part1: Particle Characterisation of a Wide Range of Engine Technologies. SAE Paper 2003-01-1889.

20. Delisle, M. 2003. New Emission Limit Philosophy based on the Total Number of Sold Particles. $7^{\text {th }}$ International ETH Conference on Combustion Generated Particles, 18-20 August 2003, Zurich, Switzerland.

\section{CONTACT}

Zissis Samaras, Professor

Laboratory of Applied Thermodynamics

Aristotle University

GR-54124 Thessaloniki Greece

Email: zisis@auth.gr

Web: http://lat.eng.auth.gr

\section{ADDITIONAL SOURCES}

Additional information on the results and technical details of the PARTICULATES project may be found at http://vergina.eng.auth.gr/mech/lat/particulates.

\section{DEFINITIONS, ACRONYMS, ABBREVIATIONS}

CADC: Common Artemis Driving Cycles

COV: Coefficient of Variance defined as standard deviation of sample over mean

CRC: Coordinating Research Council

CVS: Constant Volume Sampling

D: $\quad$ Non DPF-equipped Diesel

DC: Diffusion Charger

DISI: Direct Injection Spark Ignition

DPF: Diesel Particle Filter (equipped vehicles)

EUDC: Extra Urban Driving Cycle

G: Gasoline

NEDC: New European Driving Cycle

OEM: Original Equipment Manufacturer

PISI: Port-injection spark ignition

PM: $\quad$ Particulate matter collected in the CVS

PMP: Particle Measurement Programme

SI: Spark Ignition

TWC: Three-way catalytic converter

UDC: Urban Driving Cycle

ULEV: Ultra-Low Emission Vehicle 


\section{APPENDIX}

This appendix provides in tabular form the mean values of all measurements included in this paper and correspond to Euro 3 vehicles. The mean value of conventional D-vehicles over the cold-start NEDC using D3 fuel is taken as a reference and all other values are expressed as a percentage of this. In that respect, trends and effects of vehicle technologies, fuels and driving cycles are readily available. For example, if one wishes to calculate PM emissions from DISI vehicles, using G1 fuel over the cold UDC, then one would start with the reference state (Diesel, D3, Cold NEDC) $0.031 \mathrm{~g} / \mathrm{km}$, multiply with the reference state of DISI (G2, Cold NEDC) 0.182 and then with the percentage of the particular fuel/cycle combination (246\%). Therefore, the wished value is $0.031 \times 0.182 \times 246 \%=0.014 \mathrm{~g} / \mathrm{km}$. This method applies to all individual particle properties.

PM mass collected in the CVS following the regulated procedure for diesel vehicles

\begin{tabular}{|c|c|c|c|c|c|c|c|c|c|c|}
\hline $\mathrm{PM}[\mathrm{g} / \mathrm{km}]$ & Fuel & Cold NEDC & $\begin{array}{c}\text { Artemis } \\
\text { Road }\end{array}$ & $\begin{array}{l}\text { Artemis } \\
\text { Urban }\end{array}$ & $\begin{array}{c}\text { Artemis } \\
\text { Motorw ay }\end{array}$ & Cold EUDC & Cold UDC & Hot EUDC & Hot NEDC & Hot UDC \\
\hline \multirow{4}{*}{ Diesel } & D3 & 0.031 & $18 \%$ & $109 \%$ & $36 \%$ & $-21 \%$ & $19 \%$ & $-17 \%$ & $-4 \%$ & $9 \%$ \\
\hline & D2 & $9 \%$ & $31 \%$ & $99 \%$ & $193 \%$ & $-9 \%$ & $23 \%$ & $0 \%$ & $12 \%$ & $9 \%$ \\
\hline & D4 & $21 \%$ & $28 \%$ & $145 \%$ & $47 \%$ & $-7 \%$ & $39 \%$ & $-17 \%$ & $0 \%$ & $17 \%$ \\
\hline & D5 & $-8 \%$ & $-5 \%$ & $53 \%$ & $47 \%$ & $-33 \%$ & $16 \%$ & $-48 \%$ & $-4 \%$ & $26 \%$ \\
\hline \multirow{4}{*}{ Diesel+DPF } & D3 & 0.046 & $-17 \%$ & $64 \%$ & $-21 \%$ & $-52 \%$ & $22 \%$ & $-53 \%$ & $-39 \%$ & $-17 \%$ \\
\hline & D2 & $-22 \%$ & $847 \%$ & $30 \%$ & $6120 \%$ & $-72 \%$ & $-20 \%$ & $83 \%$ & $30 \%$ & $15 \%$ \\
\hline & D4 & $-24 \%$ & $23 \%$ & $54 \%$ & $5 \%$ & $-67 \%$ & $-23 \%$ & $-68 \%$ & $-47 \%$ & $-58 \%$ \\
\hline & D5 & $79 \%$ & $-18 \%$ & $59 \%$ & $3 \%$ & $-74 \%$ & $-82 \%$ & $-80 \%$ & $-22 \%$ & $-75 \%$ \\
\hline \multirow{3}{*}{ DISI } & G2 & 0.182 & $-63 \%$ & $48 \%$ & $-52 \%$ & $-71 \%$ & $78 \%$ & $-76 \%$ & $-50 \%$ & $-49 \%$ \\
\hline & G1 & $79 \%$ & $-70 \%$ & $-22 \%$ & $-60 \%$ & $-18 \%$ & $246 \%$ & $-31 \%$ & $-19 \%$ & $52 \%$ \\
\hline & G3 & $18 \%$ & $-48 \%$ & $6 \%$ & $28 \%$ & $-62 \%$ & $108 \%$ & $-75 \%$ & $-66 \%$ & $-47 \%$ \\
\hline \multirow{3}{*}{ Gasoline } & G2 & 0.011 & $235 \%$ & $52 \%$ & & & & & $326 \%$ & \\
\hline & G1 & $28 \%$ & $115 \%$ & $142 \%$ & $218 \%$ & $-46 \%$ & $45 \%$ & & $52 \%$ & $10 \%$ \\
\hline & G3 & $230 \%$ & $155 \%$ & $400 \%$ & $306 \%$ & $169 \%$ & $772 \%$ & & $737 \%$ & $391 \%$ \\
\hline
\end{tabular}

Active surface area recorded with the diffusion charger $(7 n m-1 \mu \mathrm{m})$

\begin{tabular}{|c|c|c|c|c|c|c|c|c|c|c|}
\hline $\begin{array}{l}\text { Active Surface } \\
{\left[\mathrm{cm}^{2} / \mathrm{km}\right]}\end{array}$ & Fuel & Cold NEDC & $\begin{array}{l}\text { Artemis } \\
\text { Road }\end{array}$ & $\begin{array}{l}\text { Artemis } \\
\text { Urban }\end{array}$ & $\begin{array}{c}\text { Artemis } \\
\text { Motorw ay }\end{array}$ & Cold EUDC & Cold UDC & Hot EUDC & Hot NEDC & Hot UDC \\
\hline \multirow{4}{*}{ Diesel } & D3 & $9.42 \mathrm{E}+04$ & $26 \%$ & $69 \%$ & $83 \%$ & $-7 \%$ & $25 \%$ & $4 \%$ & $-5 \%$ & $10 \%$ \\
\hline & $\mathrm{D} 2$ & $-9 \%$ & $36 \%$ & $65 \%$ & $290 \%$ & $-18 \%$ & $4 \%$ & $-21 \%$ & $-18 \%$ & $3 \%$ \\
\hline & D4 & $13 \%$ & $28 \%$ & $55 \%$ & $48 \%$ & $8 \%$ & $65 \%$ & $-14 \%$ & $-3 \%$ & $33 \%$ \\
\hline & D5 & $-15 \%$ & $30 \%$ & $72 \%$ & $96 \%$ & $-19 \%$ & $14 \%$ & $3 \%$ & $19 \%$ & $23 \%$ \\
\hline \multirow{4}{*}{ Diesel+DPF } & D3 & 3.72E-04 & $8 \%$ & $23 \%$ & $846 \%$ & $-26 \%$ & $73 \%$ & $-87 \%$ & $-76 \%$ & $-26 \%$ \\
\hline & $\mathrm{D} 2$ & $2204 \%$ & $110444 \%$ & $71 \%$ & $1130471 \%$ & $1058 \%$ & $1694 \%$ & $3436 \%$ & $1589 \%$ & $32 \%$ \\
\hline & D4 & $205 \%$ & $249 \%$ & $128 \%$ & $15887 \%$ & $46 \%$ & $638 \%$ & $-86 \%$ & $-76 \%$ & $22 \%$ \\
\hline & D5 & $588 \%$ & $24 \%$ & $116 \%$ & $13503 \%$ & $-67 \%$ & $1372 \%$ & $-83 \%$ & $-72 \%$ & $-55 \%$ \\
\hline \multirow{3}{*}{ DISI } & $\mathrm{G} 2$ & 8.70E-02 & $-63 \%$ & $-27 \%$ & $-78 \%$ & $-63 \%$ & $168 \%$ & $-75 \%$ & $-67 \%$ & $-42 \%$ \\
\hline & G1 & $95 \%$ & $-3 \%$ & $1 \%$ & $-7 \%$ & $-12 \%$ & $365 \%$ & $-63 \%$ & $-61 \%$ & $-41 \%$ \\
\hline & G3 & $61 \%$ & $42 \%$ & $53 \%$ & $160 \%$ & $-28 \%$ & $358 \%$ & $-73 \%$ & $-71 \%$ & $33 \%$ \\
\hline \multirow{3}{*}{ Gasoline } & G2 & 1.35E-03 & $725 \%$ & $507 \%$ & $1558 \%$ & & & & $-94 \%$ & \\
\hline & G1 & $200 \%$ & $-23 \%$ & $-15 \%$ & $-51 \%$ & $-79 \%$ & $1120 \%$ & & $-98 \%$ & $-16 \%$ \\
\hline & G3 & $242 \%$ & $60 \%$ & $2 \%$ & $1016 \%$ & $-54 \%$ & $1722 \%$ & & $-95 \%$ & $19 \%$ \\
\hline
\end{tabular}


Solid particle number concentration recorded downstream of the thermodenuder with the ELPI (30 nm - $1 \mu \mathrm{m})$

\begin{tabular}{|c|c|c|c|c|c|c|c|c|c|c|}
\hline $\begin{array}{l}\text { Solid particle } \\
\text { counts }\left[\mathrm{km}^{-1}\right]\end{array}$ & Fuel & Cold NEDC & $\begin{array}{c}\text { Artemis } \\
\text { Road } \\
\end{array}$ & $\begin{array}{l}\text { Artemis } \\
\text { Urban }\end{array}$ & $\begin{array}{c}\text { Artemis } \\
\text { Motorw ay }\end{array}$ & Cold EUDC & Cold UDC & Hot EUDC & Hot NEDC & Hot UDC \\
\hline \multirow{4}{*}{ Diesel } & D3 & $1.65 E+14$ & $-22 \%$ & $4 \%$ & $3 \%$ & $-18 \%$ & $26 \%$ & $-33 \%$ & $-21 \%$ & $-14 \%$ \\
\hline & D2 & $-10 \%$ & $1 \%$ & $24 \%$ & $-10 \%$ & $-23 \%$ & $12 \%$ & $-21 \%$ & $-7 \%$ & $-5 \%$ \\
\hline & D4 & $7 \%$ & $36 \%$ & $456 \%$ & $35 \%$ & $-35 \%$ & $-6 \%$ & $-12 \%$ & $4 \%$ & $1 \%$ \\
\hline & D5 & $-24 \%$ & $5 \%$ & $29 \%$ & $13 \%$ & $-38 \%$ & $-8 \%$ & $-8 \%$ & $4 \%$ & $3 \%$ \\
\hline \multirow{4}{*}{ Diesel+DPF } & D3 & $9.29 \mathrm{E}-04$ & $-41 \%$ & $-16 \%$ & $-30 \%$ & $-64 \%$ & $110 \%$ & $-70 \%$ & $-63 \%$ & $-41 \%$ \\
\hline & D2 & $32 \%$ & $-46 \%$ & $-22 \%$ & $-46 \%$ & $-73 \%$ & $525 \%$ & $-75 \%$ & $-70 \%$ & $-61 \%$ \\
\hline & D4 & $61 \%$ & $-56 \%$ & $-34 \%$ & $268 \%$ & $-56 \%$ & $178 \%$ & $-77 \%$ & $-72 \%$ & $-49 \%$ \\
\hline & D5 & $88 \%$ & $-63 \%$ & $-35 \%$ & $-36 \%$ & $-69 \%$ & $643 \%$ & $-72 \%$ & $-70 \%$ & $-35 \%$ \\
\hline \multirow{3}{*}{ DISI } & G2 & 1.04E-01 & $-53 \%$ & $-12 \%$ & $-71 \%$ & $-80 \%$ & $19 \%$ & $-88 \%$ & $-72 \%$ & $-79 \%$ \\
\hline & G1 & $-8 \%$ & $-62 \%$ & $-43 \%$ & $-72 \%$ & $-63 \%$ & $81 \%$ & $-74 \%$ & $-69 \%$ & $-64 \%$ \\
\hline & G3 & $-11 \%$ & $-40 \%$ & $-24 \%$ & $-74 \%$ & $-74 \%$ & $54 \%$ & $-90 \%$ & $-79 \%$ & $-60 \%$ \\
\hline \multirow{3}{*}{ Gasoline } & G2 & 1.21E-02 & $1304 \%$ & $903 \%$ & $975 \%$ & & & & $-96 \%$ & \\
\hline & $\mathrm{G} 1$ & $-89.5 \%$ & $-95.6 \%$ & $-92.0 \%$ & $-99.0 \%$ & $-99.0 \%$ & $-62.6 \%$ & & $-99.4 \%$ & $-93.7 \%$ \\
\hline & G3 & $-86.3 \%$ & $-92.0 \%$ & $-91.7 \%$ & $-94.9 \%$ & $-99.0 \%$ & $-42.4 \%$ & & $-97.8 \%$ & $-97.3 \%$ \\
\hline
\end{tabular}

Total particle number counts recorded with the CPC (>7 nm)

\begin{tabular}{|c|c|c|c|c|c|c|c|c|c|c|}
\hline $\begin{array}{l}\text { Total particle } \\
\text { counts }\left[\mathrm{km}^{-1}\right]\end{array}$ & Fuel & Cold NEDC & $\begin{array}{l}\text { Artemis } \\
\text { Road }\end{array}$ & $\begin{array}{c}\text { Artemis } \\
\text { Urban }\end{array}$ & $\begin{array}{c}\text { Artemis } \\
\text { Motorw ay }\end{array}$ & Cold EUDC & Cold UDC & Hot EUDC & Hot NEDC & Hot UDC \\
\hline \multirow{4}{*}{ Diesel } & D3 & $1.14 \mathrm{E}+14$ & $5 \%$ & $16 \%$ & $126 \%$ & $-21 \%$ & $30 \%$ & $-28 \%$ & $-11 \%$ & $-1 \%$ \\
\hline & $\mathrm{D} 2$ & $50 \%$ & $44 \%$ & $31 \%$ & $948 \%$ & $64 \%$ & $40 \%$ & $53 \%$ & $33 \%$ & $12 \%$ \\
\hline & D4 & $-8 \%$ & $22 \%$ & $555 \%$ & $211 \%$ & $-38 \%$ & $1 \%$ & $-37 \%$ & $-7 \%$ & $-1 \%$ \\
\hline & D5 & $-9 \%$ & $23 \%$ & $34 \%$ & $189 \%$ & $-27 \%$ & $0 \%$ & $-10 \%$ & $9 \%$ & $16 \%$ \\
\hline \multirow{4}{*}{ Diesel+DPF } & D3 & 7.35E-04 & $-51 \%$ & $-58 \%$ & $2453 \%$ & $-11 \%$ & $49 \%$ & $-98 \%$ & $-98 \%$ & $-62 \%$ \\
\hline & $\mathrm{D} 2$ & $998 \%$ & $213239 \%$ & $-76 \%$ & $1724519 \%$ & $3047 \%$ & $273 \%$ & $9266 \%$ & $4698 \%$ & $-87 \%$ \\
\hline & D4 & $135 \%$ & $17807 \%$ & $-20 \%$ & $347816 \%$ & $9 \%$ & $189 \%$ & $-85 \%$ & $-93 \%$ & $-9 \%$ \\
\hline & D5 & $2 \%$ & $-51 \%$ & $5 \%$ & $105102 \%$ & $-89 \%$ & $267 \%$ & $-98 \%$ & $-82 \%$ & $-97 \%$ \\
\hline \multirow{3}{*}{ DISI } & G2 & 1.34E-01 & $-30 \%$ & $28 \%$ & $599 \%$ & $-59 \%$ & $80 \%$ & $-66 \%$ & $-49 \%$ & $-20 \%$ \\
\hline & G1 & $27 \%$ & $-12 \%$ & $14 \%$ & $-7 \%$ & $-24 \%$ & $138 \%$ & $-46 \%$ & $-38 \%$ & $-8 \%$ \\
\hline & G3 & $-9 \%$ & $-33 \%$ & $-28 \%$ & $-7 \%$ & $-42 \%$ & $110 \%$ & $-68 \%$ & $-58 \%$ & $-51 \%$ \\
\hline \multirow{3}{*}{ Gasoline } & G2 & 2.00E-02 & $551 \%$ & $298 \%$ & $5203 \%$ & & & & $-95.5 \%$ & \\
\hline & G1 & $-8 \%$ & $-74 \%$ & $-71 \%$ & $-83 \%$ & $-90 \%$ & $247 \%$ & & $-96.5 \%$ & $-66 \%$ \\
\hline & G3 & $-17 \%$ & $-54 \%$ & $-62 \%$ & $244 \%$ & $-91 \%$ & $328 \%$ & & $-95.5 \%$ & $-78 \%$ \\
\hline
\end{tabular}

